ARTICLE

Received 29 Jan 2014 | Accepted 6 Jun 2014 | Published 8 Jul $2014 \quad$ DOl: 10.1038/ncomms5312

\title{
Highly efficient non-rare-earth red emitting phosphor for warm white light-emitting diodes
}

Haomiao Zhu', Chun Che Lin'², Wenqin Luo', Situan Shu', Zhuguang Liu', Yongsheng Liu', Jintao Kong ${ }^{1}$, En Ma1, Yongge Cao', Ru-Shi Liu² \& Xueyuan Chen ${ }^{1}$

$\mathrm{Mn}^{4+}$-activated fluoride compounds, as an alternative to commercial (oxy)nitride phosphors, are emerging as a new class of non-rare-earth red phosphors for high-efficacy warm white LEDs. Currently, it remains a challenge to synthesize these phosphors with high photoluminescence quantum yields through a convenient chemical route. Herein we propose a general but convenient strategy based on efficient cation exchange reaction, which had been originally regarded only effective in synthesizing nano-sized materials before, for the synthesis of $\mathrm{Mn}^{4+}$-activated fluoride microcrystals such as $\mathrm{K}_{2} \mathrm{TiF}_{6}, \mathrm{~K}_{2} \mathrm{SiF}_{6}, \mathrm{NaGdF}_{4}$ and $\mathrm{NaYF}_{4}$. Particularly we achieve a photoluminescence quantum yield as high as $98 \%$ for $\mathrm{K}_{2} \mathrm{TiF}_{6}: \mathrm{Mn}^{4+}$. By employing it as red phosphor, we fabricate a high-performance white LED with low correlated colour temperature $(3,556 \mathrm{~K})$, high-colour-rendering index $\left(R_{\mathrm{a}}=81\right)$ and luminous efficacy of $116 \mathrm{~lm} \mathrm{~W} \mathrm{~W}^{-1}$. These findings show great promise of $\mathrm{K}_{2} \mathrm{TiF}_{6}: \mathrm{Mn}^{4+}$ as a commercial red phosphor in warm white LEDs, and open up new avenues for the exploration of novel non-rare-earth red emitting phosphors.

\footnotetext{
${ }^{1}$ Key Laboratory of Optoelectronic Materials Chemistry and Physics, Key Laboratory of Design and Assembly of Functional Nanostructures, Fujian Institute of Research on the Structure of Matter, Chinese Academy of Sciences, Fuzhou, Fujian 350002, China. ${ }^{2}$ Department of Chemistry, National Taiwan University, Taipei 106, Taiwan. Correspondence and requests for materials should be addressed to X.C. (email: xchen@fjirsm.ac.cn) or to R.S.L. (email: rsliu@ntu.edu.tw).
} 
S olid-state white light-emitting diodes (LEDs) are nextgeneration lighting devices for replacing the traditional incandescent and fluorescent lamps due to their superior properties such as energy-saving, robust, long-lifetime and environment-friendly features ${ }^{1-13}$. Nowadays, a blue diode chip combined with $\mathrm{Y}_{3} \mathrm{Al}_{5} \mathrm{O}_{12}: \mathrm{Ce}^{3+}$ (YAG: $\mathrm{Ce}^{3+}$ ) yellow phosphor is still the most mature method for fabricating commercial white LEDs. YAG: $\mathrm{Ce}^{3+}$ is an excellent phosphor for blue-chip excitation with high photoluminescence (PL) quantum yield (QY) and good thermal stability. However, because of the lack of

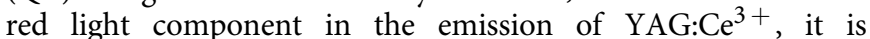
notoriously difficult to make warm white LEDs with highcolour-rendering index (CRI, $R_{\mathrm{a}}>80$ ) and low correlated colour temperature $(\mathrm{CCT}<4,500 \mathrm{~K})$, both of which are key requirements for some important applications such as indoor lighting. This difficulty can be completely overcome by adding a suitable red phosphor in LEDs to complement the red light component. To this end, great efforts have been made to exploit novel rare-earthdoped red phosphors, and the most successful materials are $\mathrm{Eu}^{2+}$ - or $\mathrm{Ce}^{3+}$-doped (oxy)nitride compounds ${ }^{14-19}$, typically $\mathrm{CaAlSiN}_{3}: \mathrm{Eu}^{2+}$ (ref. 20). Albeit commercialized in recent years, the $\mathrm{CaAlSiN}_{3}: \mathrm{Eu}^{2+}$ phosphor still has several drawbacks: First, its emission spectrum is very broad (full-width at halfmaximum $=\sim 80 \mathrm{~nm}$ ) and a large part of the spectrum is beyond $650 \mathrm{~nm}$ in wavelength and insensitive to human eyes ${ }^{20-22}$, thereby decreasing the luminous efficiency of radiation (LER) ${ }^{23}$. Second, the absorption of the phosphor covers the spectral range of 200-650 nm; therefore serious re-absorption will take place when this phosphor is mixed with other green or yellow phosphors, which causes colour change and lower luminous efficacy of LEDs ${ }^{24,25}$. Third, the rigorous synthesis conditions of nitride compounds increase its production cost. Generally, $\mathrm{CaAlSiN}_{3}: \mathrm{Eu}^{2}+$ phosphor was prepared by firing a powder mixture of $\mathrm{Si}_{3} \mathrm{~N}_{4}, \mathrm{AlN}, \mathrm{Ca}_{3} \mathrm{~N}_{2}$ and EuN raw materials at 1,600 $1,800^{\circ} \mathrm{C}$ for $2 \mathrm{~h}$ under $0.5 \mathrm{MPa}$ nitrogen atmosphere ${ }^{26}$. To circumvent the above drawbacks, an ideal red phosphor with relatively narrow absorption and emission bands, a high PL QY and low-production cost are highly desired for warm white LEDs.

$\mathrm{Mn}^{4+}$ belongs to transition metal ion with outer $3 \mathrm{~d}^{3}$ electron configuration. An interesting spectral feature of $\mathrm{Mn}^{4+}$ is that it exhibits both broadband excitation and sharp emission lines due to its distinct electronic structure. Additionally, their optical properties are strongly influenced by local crystal field environments. For example, the excitation and emission peaks of $\mathrm{Mn}^{4+}$ in oxide hosts are usually at $\sim 300$ and $\sim 650 \mathrm{~nm}$, respectively ${ }^{27-29}$. However, when $\mathrm{Mn}^{4+}$ ions are situated at fluoride hosts with octahedral coordination, they exhibit the most intense broadband excitation at $\sim 460 \mathrm{~nm}$ with a bandwidth of $\sim 50 \mathrm{~nm}$ and very sharp emission lines peaking at $\sim 630 \mathrm{~nm}$ as a result of weaker crystal field for $\mathrm{Mn}^{4+}$ (refs 30-32). These unique optical characteristics meet the spectral requirements for an ideal red phosphor and thus enable the family of $\mathrm{Mn}^{4+}$-doped fluoride compounds as promising candidates of red emitting phosphors for blue-chip excited warm white LEDs with high LER. So far, most of previous efforts were devoted to the preparation and optical properties investigation of $\mathrm{Mn}^{4+}$-doped fluoride phosphors $^{30-35}$. To the best of our knowledge, warm white LEDs based on $\mathrm{Mn}^{4+}$-doped red phosphors with a luminous efficacy higher than $90 \mathrm{~lm} \mathrm{~W}^{-1}$, a prerequisite for further commercialization, had never been achieved before.

The $\mathrm{K}_{2} \mathrm{TiF}_{6}$ crystal has a hexagonal structure with $P \quad \overline{3} \mathrm{~m} 1$ space group, and the $\mathrm{Ti}^{4+}$ ion is coordinated with six $\mathrm{F}^{-}$ions to form a regular octahedron ${ }^{36}$. It is a suitable host for $\mathrm{Mn}^{4+}$ doping in view of the same valence and similar ionic radius between $\mathrm{Ti}^{4+}\left(0.0605 \mathrm{~nm}\right.$ with six coordination) and $\mathrm{Mn}^{4+}$ $(0.0530 \mathrm{~nm} \text { with six coordination })^{37}$. Currently, it remains a great challenge to synthesize this phosphor with high PL QY through a convenient chemical route. Particularly, the synthetic approaches previously established are not practical for its low-cost mass production. For instance, $\mathrm{K}_{2} \mathrm{TiF}_{6}: \mathrm{Mn}^{4+}$ was usually prepared via cocrystallization $^{30,35,38,39}$. The fluoride host and source materials of $\mathrm{Mn}^{4+}$ (generally alkali metal hexafluoromanganates) were dissolved in concentrated hydrofluoric acid (HF) solution and then evaporated slowly to dryness. As such, the whole preparation process was time-consuming, and massive evaporated HF gas must be handled with great care. Another approach for the synthesis of this phosphor is to etch $\mathrm{TiO}_{2}$ in $\mathrm{HF}$ solution mixed with $\mathrm{KMnO}_{4}$ (ref. 34). However, its production yield is very low because metal oxides usually have large solubility in concentrated HF solution. Therefore, a general but convenient synthesis method is highly demanded for $\mathrm{K}_{2} \mathrm{TiF}_{6}: \mathrm{Mn}^{4+}$ as well as other $\mathrm{Mn}^{4+}$-activated fluoride red phosphors.

On the other hand, a comprehensive understanding of the electronic structure and optical properties of $\mathrm{Mn}^{4+}$ emitters in fluoride phosphors, which is crucial to improving their PL QYs for further applications, is still lacking. For instance, the mechanism behind the abnormal temperature-dependent PL intensity behaviour of $\mathrm{Mn}^{4+}$ ions remains unclear till now ${ }^{27}$. An in-depth investigation of the optical properties and device performance of $\mathrm{Mn}^{4+}$-activated phosphors will promote the application of this cheap and abundant resource in the field of solid-state lighting, thus reduce the consumption of expensive rare-earth such as Eu.

In this work, we propose a unique method based on cation exchange reaction for preparing highly efficient $\mathrm{K}_{2} \mathrm{TiF}_{6}: \mathrm{Mn}^{4+}$ red phosphor with a PL QY up to $98 \%$. We also demonstrate that such an approach is general to the synthesis of various $\mathrm{Mn}^{4+}$-activated fluoride phosphors such as $\mathrm{K}_{2} \mathrm{SiF}_{6}: \mathrm{Mn}^{4+}$, $\mathrm{NaGdF}_{4}: \mathrm{Mn}^{4+}$ and $\mathrm{NaYF}_{4}: \mathrm{Mn}^{4+}$. Particularly, the fine electronic/vibronic structures and excited-state dynamics of $\mathrm{Mn}^{4+}$ ions in $\mathrm{K}_{2} \mathrm{TiF}_{6}$ host are revealed for the first time by means of highresolution optical spectroscopy. By employing $\mathrm{K}_{2} \mathrm{TiF}_{6}: \mathrm{Mn}^{4+}$ as red phosphor, we realize a high-performance warm white LED with low CCT $(3,556 \mathrm{~K})$, high CRI $\left(R_{\mathrm{a}}=81\right)$ and luminous efficacy of $116 \mathrm{~lm} \mathrm{~W}^{-1}$, which presents a substantial advance towards its commercial application.

\section{Results}

Synthesis strategy. The main difficulty for synthesizing $\mathrm{Mn}^{4+}$. activated fluoride compounds lies in that $\mathrm{Mn}$ has diverse valence states, thus valence change of $\mathrm{Mn}^{4+}$ often occurs during synthesis, resulting in undesired byproducts. Although the doping of $\mathrm{Mn}^{4+}$ has been realized in oxide compounds through solid-state reaction at high temperature, it is unpractical for synthesizing $\mathrm{Mn}^{4+}$-activated fluoride compounds through this route because hazard and corrosive HF gas was used to prevent the oxidation of products ${ }^{40}$. In contrast, cation exchange reaction has been proved to be a convenient method for lanthanide doping in nano-sized fluoride crystals ${ }^{41,42}$. It was well established that efficient cation exchange can only take place in nano-sized materials ${ }^{43,44}$. Interestingly, we recently found that the cation exchange approach can also be applicable for the synthesis of micrometre-sized materials with unusually fast reaction rate. To demonstrate this, we employed this approach to the synthesis of $\mathrm{K}_{2} \mathrm{TiF}_{6}: \mathrm{Mn}^{4+}$ microcrystals. The preparation was carried out by simply mixing $\mathrm{K}_{2} \mathrm{TiF}_{6}$ host with a small volume of $\mathrm{HF}$ solution dissolved with $\mathrm{K}_{2} \mathrm{MnF}_{6}$ powders. After stirring for $20 \mathrm{~min}$, a muddy mixture was formed, and then heated at $70^{\circ} \mathrm{C}$ for $3 \mathrm{~h}$, which afforded the final product of $\mathrm{K}_{2} \mathrm{TiF}_{6}: \mathrm{Mn}^{4+}$. It is worthy of emphasizing that only a small portion of $\mathrm{K}_{2} \mathrm{TiF}_{6}$ raw powders was dissolved in HF solution containing $\mathrm{Mn}^{4+}$ ions (the solubility of 
$\mathrm{K}_{2} \mathrm{TiF}_{6}$ in 49 wt.\% $\mathrm{HF}$ solution is $\sim 0.17 \mathrm{~g} \mathrm{ml}^{-1}$ at room temperature (RT)), and cocrystallization of $\mathrm{K}_{2} \mathrm{TiF}_{6}: \mathrm{Mn}^{4+}$ may occur for this portion once the mixture was directly heated to dryness. However, for the undissolved portion, we assume that the cation exchange reaction, namely, the replacement of $\mathrm{Ti}^{4+}$ ions in $\mathrm{K}_{2} \mathrm{TiF}_{6}$ crystals with the $\mathrm{Mn}^{4+}$ ions in the solution, is responsible for the doping of $\mathrm{Mn}^{4+}$.

To verify our hypothesis, we carried out a proof-of-concept experiment. The $\mathrm{K}_{2} \mathrm{TiF}_{6}$ powders were immersed in $\mathrm{HF}$ solution containing $\mathrm{Mn}^{4+}$ ions (the atom percent of $\mathrm{Mn}$ is $5.50 \%$ ). After cation exchange reaction at RT for $3 \mathrm{~min}$ under stirring, the powders were isolated instantly through vacuum filtration. It was observed that the colour of the mixture solution changed from brown to light-yellow, indicating a remarkable decrease of the $\mathrm{Mn}^{4+}$ concentration in the solution. Accordingly, the colour of the powders was observed to change from white to yellow after cation exchange (Fig. 1a,b). This reaction process was dynamically demonstrated by illuminating the $\mathrm{K}_{2} \mathrm{TiF}_{6}$ powders with 455 $\mathrm{nm}$ blue light under stirring, which showed a remarkable increase in red light emission within $3 \mathrm{~min}$ (Supplementary Movie 1). The $\mathrm{X}$-ray diffraction (XRD) pattern of the final powder product confirmed that it remained pure in hexagonal $\mathrm{K}_{2} \mathrm{TiF}_{6}$ phase (Supplementary Fig. 1). Under illumination with the 455-nm light, the powders show bright red emission, indicating the successful doping of $\mathrm{Mn}^{4+}$ into the crystal lattice of $\mathrm{K}_{2} \mathrm{TiF}_{6}$. The $\mathrm{Mn}^{4+}$ concentration in the as-synthesized powders was determined to be 3.70 at.\% (that is, $67 \%$ of the $\mathrm{Mn}^{4+}$ ions in the precursor solution) by means of inductively coupled plasmaatomic emission spectroscopy (ICP-AES). The observation of such a high $\mathrm{Mn}^{4}+$ content within the short reaction time shows unambiguously that the cation exchange occurred with an unusually fast reaction rate. Figure $1 \mathrm{c}$ schematically illustrates this cation exchange procedure for synthesizing $\mathrm{Mn}^{4+}$-activated fluoride compounds.

Different from the traditional cocrystallization method, our strategy based on cation exchange shows two distinct advantages: (1) The consumption of HF solution per gram of $\mathrm{K}_{2} \mathrm{TiF}_{6}: \mathrm{Mn}^{4+}$ product $\left(\sim 0.36 \mathrm{mlg}^{-1}\right)$ is 17 times lower than that of cocrystallization method $\left(\sim 6 \mathrm{ml} \mathrm{g}^{-1}\right)$, which is very beneficial to the waste processing of the hazard HF gas produced during synthesis; (2) The synthetic time is significantly shortened and the whole procedure is well controlled, which are crucial for mass production of $\mathrm{K}_{2} \mathrm{TiF}_{6}: \mathrm{Mn}^{4+}$. This strategy can be further extended for synthesizing other $\mathrm{Mn}^{4+}$-activated fluoride materials such as $\mathrm{K}_{2} \mathrm{SiF}_{6}: \mathrm{Mn}^{4+}, \mathrm{NaGdF}_{4}: \mathrm{Mn}^{4+}$ and $\mathrm{NaYF}_{4}: \mathrm{Mn}^{4+}$. Similarly, XRD patterns and PL spectra of these samples show the pure crystalline phase of each host and typical sharp emissions of $\mathrm{Mn}^{4+}$ at $\sim 630 \mathrm{~nm}$ on $455-\mathrm{nm}$ excitation (Supplementary

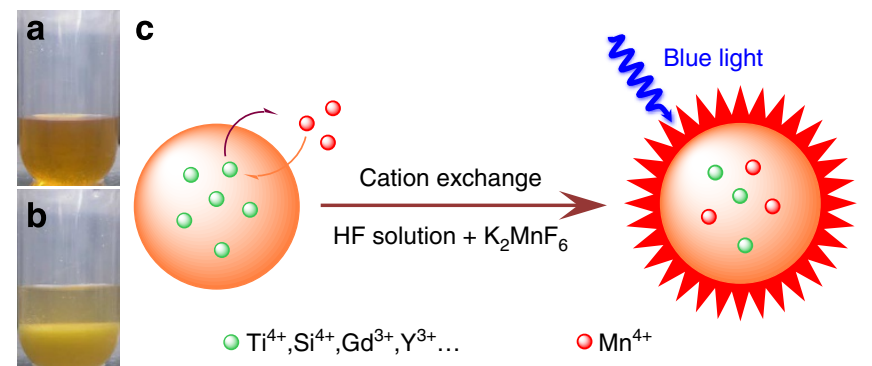

Figure 1 | Synthesis of $\mathbf{M n}^{\mathbf{4}+}$-activated red phosphors based on the strategy of cation exchange. Photographs of the $\mathrm{HF}$ solution dissolved with $\mathrm{K}_{2} \mathrm{MnF}_{6}$ crystals (a) and the same solution containing $\mathrm{K}_{2} \mathrm{TiF}_{6}$ powders after cation exchange reaction for $3 \mathrm{~min}$ (b). (c) Schematic illustration of the cation exchange procedure for synthesizing $\mathrm{Mn}^{4+}$-activated fluoride compounds.
Figs 2-4 and Methods). All these results prove that the proposed cation exchange strategy is universal for the synthesis of $\mathrm{Mn}^{4+}$. activated fluoride phosphors.

Structural characterization. We synthesized five $\mathrm{K}_{2} \mathrm{TiF}_{6}: \mathrm{Mn}^{4+}$ samples with various $\mathrm{Mn}^{4}$ concentrations through cation exchange route. Compositional analyses through ICP-AES reveal that the $\mathrm{Mn}^{4+}$ concentrations of the samples were $0.72,1.40$, $2.10,5.50$ and 6.50 at.\%, respectively. The XRD patterns of these five samples along with the pure $\mathrm{K}_{2} \mathrm{TiF}_{6}$ sample and $\mathrm{K}_{2} \mathrm{MnF}_{6}$ crystal are compared in Fig. 2a. All the diffraction peaks of $\mathrm{K}_{2} \mathrm{TiF}_{6}: \mathrm{Mn}^{4+}$ samples can be indexed to $P \overline{3} \mathrm{~m} 1$ space group of hexagonal $\mathrm{K}_{2} \mathrm{TiF}_{6}$ phase (JCPDS No. 00-008-0488). No traces of $\mathrm{K}_{2} \mathrm{MnF}_{6}$ residual and other impurity phases were observed. The crystal structure of $\mathrm{K}_{2} \mathrm{TiF}_{6}$ viewed from [110] direction is shown in Fig. 2b. Each $\mathrm{Ti}^{4+}$ ion is surrounded by six $\mathrm{F}^{-}$ions resulting in only one kind of $\mathrm{TiF}_{6}^{2-}$ octahedral structure. Notably, the $\mathrm{K}^{+}$ion is at the centre of 12 nearest neighbour $\mathrm{F}^{-}$ions forming a nearly regular polyhedron. The scanning electron microscope image of the 5.50 at.\% sample indicates that the particle size is primarily in the range of $10-20 \mu \mathrm{m}$ (Fig. 2c). The sample shows a uniform yellow tint under natural light illumination (Fig. 2d). While under blue light ( $455 \mathrm{~nm})$ excitation, it emits brilliant red light, indicating high emission efficiency (Fig. 2e).

To reveal whether the $\mathrm{Mn}^{4+}$ ions are located on the surface of or distributed uniformly across the $\mathrm{K}_{2} \mathrm{TiF}_{6}: \mathrm{Mn}^{4+}$ crystals synthesized through cation exchange, we first compared the XRD patterns of the samples and found a slight shift of the diffraction peaks to higher angles with the increase of $\mathrm{Mn}^{4+}$ doping concentrations (Fig. 2a and enlarged XRD patterns in Supplementary Fig. 5a). Accordingly, the fitted cell volume of the samples by the JADE software also decreases from $133.43 \AA^{3}$ for the pure sample to $133.04 \AA^{3}$ for the 6.50 at.\% sample (Supplementary Fig. 5b-d). This observation is consistent with the expected structural change induced by the substitution of a smaller cation $\left(\mathrm{Mn}^{4+}, 0.0530 \mathrm{~nm}\right)$ for a larger cation $\left(\mathrm{Ti}^{4+}\right.$, $0.0605 \mathrm{~nm})$ in the crystalline lattice. To investigate the $\mathrm{Mn}^{4+}$ distribution in the crystals, we synthesized a 6.83 at.\% $\mathrm{K}_{2} \mathrm{TiF}_{6}: \mathrm{Mn}^{4+}$ sample through cation exchange for $20 \mathrm{~min}$ and washed this sample with HF solution (16 wt.\%) to dissolve the surface of the crystals (Supplementary Methods). The colour of the crystals before and after washing is nearly the same (Supplementary Fig. 6a-c) and ICP-AES analyses show that the $\mathrm{Mn}^{4}+$ concentration in the crystals remains nearly unchanged (6.96 at.\%) after being washed twice. On the contrary, in a control experiment, the $\mathrm{Mn}^{4+}$ concentration was found to decrease significantly from 0.45 to 0.02 at.\% in the sample synthesized through cation exchange for only $10 \mathrm{~s}$, which was also corroborated by the disappearance of red light emission for this sample after acid-washing treatment (Supplementary Fig. 6d-f). These results exclude the possibility of the $\mathrm{Mn}^{4+}$ aggregation on the surface of the 6.96 at.\% sample and suggest that $\mathrm{Mn}^{4+}$ ions are distributed uniformly across the crystals. To further visualize the $\mathrm{Mn}^{4+}$ distribution in the crystals, we carried out scanning transmission electron microscopy and energy dispersive spectroscopy analyses for the 6.96 at.\% sample. Both elemental line scanning and mapping measurements show similar concentration distribution of the $\mathrm{Mn}$ to that of the Ti element (Supplementary Fig. 7). The molar ratio of $\mathrm{Mn}$ to $\mathrm{Ti}$ was roughly estimated to be $\sim 10 \%$ based on the calibrated signal intensities of energy dispersive spectroscopy, which is basically consistent with the $\mathrm{Mn}^{4+}$ concentration (6.96 at.\%) measured by ICP-AES. All above results prove that $\mathrm{Mn}^{4+}$ ions are distributed uniformly across the crystals synthesized through cation exchange for $20 \mathrm{~min}$ 
a

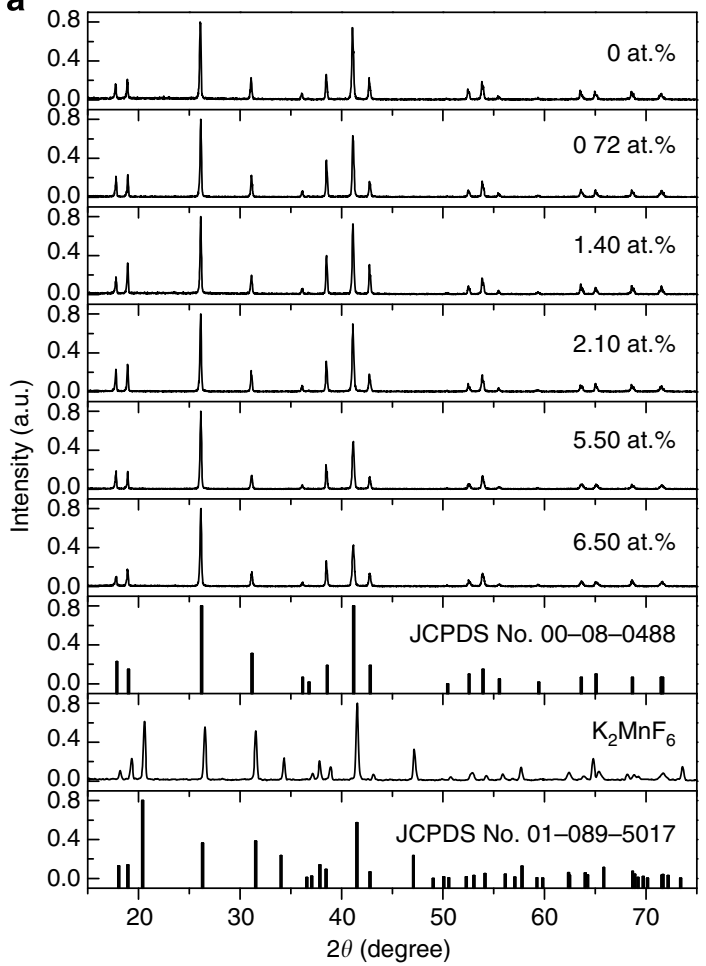

b
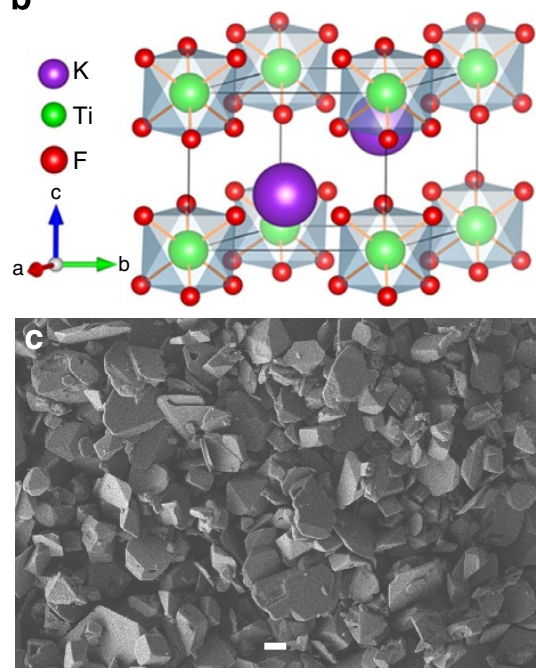

d

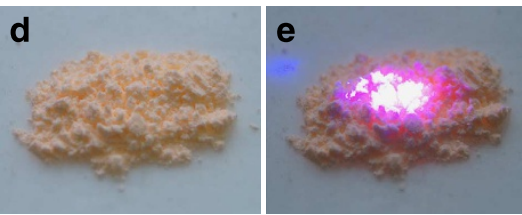

Figure 2 I Structure and morphology of the synthesized $\mathbf{K}_{\mathbf{2}} \mathbf{T i F}_{\mathbf{6}}: \mathbf{M n}^{\mathbf{4}}+$ phosphors. (a) X-ray diffraction patterns of the $\mathrm{K}_{2} \mathrm{MnF}_{6} \mathrm{Crystal}_{\text {and }} \mathrm{K}_{2} \mathrm{TiF}_{6}$ samples doped with various $\mathrm{Mn}^{4+}$ contents. All diffraction peaks match well with the standard patterns of $\mathrm{K}_{2} \mathrm{MnF}_{6}$ (JCPDS No. 01-089-5017) and tetragonal-phase $\mathrm{K}_{2} \mathrm{TiF}_{6}$ (JCPDS No. 00-008-0488), respectively. (b) Crystal structure of $\mathrm{K}_{2} \mathrm{TiF}_{6}$ unit cell viewed in [110] direction. (c) Representative scanning electron microscope image of the $\mathrm{K}_{2} \mathrm{TiF}_{6}: \mathrm{Mn}^{4+}\left(5.5\right.$ at.\%) sample. Scale bar, $10 \mu \mathrm{m}$. Photographs of the $\mathrm{K}_{2} \mathrm{TiF}: \mathrm{Mn}^{4}+(5.50$ at. $\%)$ sample under natural light (d) and 455-nm blue light (e) illumination, respectively. a.u., arbitrary unit.

\begin{tabular}{|c|c|c|c|c|c|}
\hline Samples (at.\%) & 0.72 & 1.40 & 2.10 & 5.50 & 6.50 \\
\hline Absorption efficiency & $29 \%$ & $36 \%$ & $46 \%$ & $54 \%$ & $60 \%$ \\
\hline PL QY & $96 \%$ & $98 \%$ & $96 \%$ & $93 \%$ & $78 \%$ \\
\hline Lifetime (ms) & 5.90 & 6.00 & 5.80 & 5.70 & 5.20 \\
\hline
\end{tabular}

PL QY. PL QY is a key parameter to evaluate a phosphor material. It is defined as the ratio of emitted photons to absorbed ones. For commercial phosphors such as YAG: $\mathrm{Ce}^{3+}$, the PL QY is usually larger than $90 \%$. Unfortunately, currently no experimental PL QY is available for $\mathrm{K}_{2} \mathrm{TiF}_{6}: \mathrm{Mn}^{4+}$. We measured the absolute PL QY of the samples using an integrating sphere at RT and the results are listed in Table 1 . The samples doped with the $\mathrm{Mn}^{4+}$ concentration of 5.50 at.\% or lower show extremely high PL QYs ranging from 93 to $98 \%$, which are comparable or superior to that of commercial YAG: $\mathrm{Ce}^{3+}$ phosphor. As the $\mathrm{Mn}^{4+}$ concentration increased from 5.50 to 6.50 at.\%, the QY decreased dramatically from 93 to $78 \%$, due to the concentration quenching effect at high doping concentration. We also measured RT PL decays from the emitting state ${ }^{2} \mathrm{E}_{\mathrm{g}}$ in these samples (Supplementary Fig. 8), and each PL decay time was determined based on single exponential fit of the decay (Table 1). It shows clearly that the PL lifetime of the 6.50 at.\% sample is significantly shorter than those of other samples, indicating the largest nonradiative transition probability and thus the lowest PL QY of this sample. It is worthy of emphasizing that no decline of PL QYs was observed for these five samples after being kept at ambient conditions for over 1 year. This indicates that the $\mathrm{K}_{2} \mathrm{TiF}_{6}: \mathrm{Mn}^{4+}$ phosphor is stable in the air.

Electronic and vibronic structures of $\mathbf{M n}^{\mathbf{4}+}$. When $\mathrm{Mn}^{4+}$ ions are situated at hosts with octahedral coordination, the dependence of energy levels of $\mathrm{Mn}^{4+}$ on crystal field strength can be well illustrated by Tanabe-Sugano energy diagram (Fig. 3a) ${ }^{45}$. It shows clearly that the energies of most multiplets are strongly dependent on crystal field strength except ${ }^{2} \mathrm{~T}_{1}$ and ${ }^{2} \mathrm{E}_{\mathrm{g}}$ levels. Particularly, the optical characteristics of $\mathrm{Mn}^{4+}$ in fluoride hosts can be inferred from their configurational coordinate diagrams (Fig. 3b $)^{46}$. The ${ }^{2} \mathrm{E}_{\mathrm{g}},{ }^{2} \mathrm{~T}_{1},{ }^{2} \mathrm{~T}_{2}$ and ${ }^{4} \mathrm{~A}_{2}$ levels are derived from the $t_{2}^{3}$ electronic orbital, whereas the ${ }^{4} \mathrm{~T}_{1}$ and ${ }^{4} \mathrm{~T}_{2}$ levels are formed from another $t_{2}^{2} e$ orbital ${ }^{46}$. As such, a large lateral displacement can be observed between the parabolas of ground state ${ }^{4} \mathrm{~A}_{2}$ and ${ }^{4} \mathrm{~T}_{1}$ ( or ${ }^{4} \mathrm{~T}_{2}$ ), while a small displacement between the parabolas of ${ }^{4} \mathrm{~A}_{2}$ and ${ }^{2} \mathrm{E}_{\mathrm{g}}$ (or ${ }^{2} \mathrm{~T}_{1},{ }^{2} \mathrm{~T}_{2}$ ). Larger displacement implies stronger electron-phonon interaction (namely, larger Huang-Rhys factor) and thus larger spectral bandwidth of the transition ${ }^{46}$. Additionally, according to the spin selection rule of $\Delta S=0$, the transitions between ${ }^{4} \mathrm{~T}_{1},{ }^{4} \mathrm{~T}_{2}$ and ground ${ }^{4} \mathrm{~A}_{2}$ levels are spinallowed, thus intense excitation or absorption bands with relatively large bandwidths are expected between these levels. On excitation to ${ }^{4} \mathrm{~T}_{1}$ or ${ }^{4} \mathrm{~T}_{2}$ levels, the excited ions usually relax non-radiatively to ${ }^{2} \mathrm{E}_{\mathrm{g}}$ followed by the spin-forbidden ${ }^{2} \mathrm{E}_{\mathrm{g}} \rightarrow{ }^{4} \mathrm{~A}_{2}$ transition characterized by sharp emission lines.

We measured the RT excitation and emission spectra of $\mathrm{K}_{2} \mathrm{TiF}_{6}: \mathrm{Mn}^{4+}$ and the results are in good agreement with the above predicted optical characteristics. There are three intense excitation bands of $\mathrm{K}_{2} \mathrm{TiF}_{6}: \mathrm{Mn}^{4+}(0.72$ at.\%) in the range of 200-550 nm (Fig. 3c). The 362 and $468 \mathrm{~nm}$ bands are due to the 
a

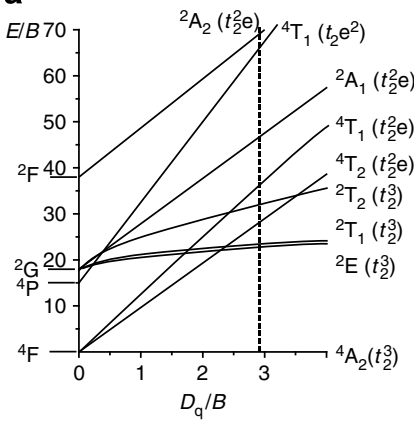

b

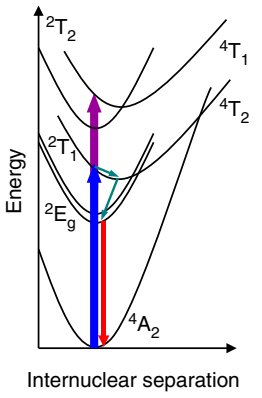

C

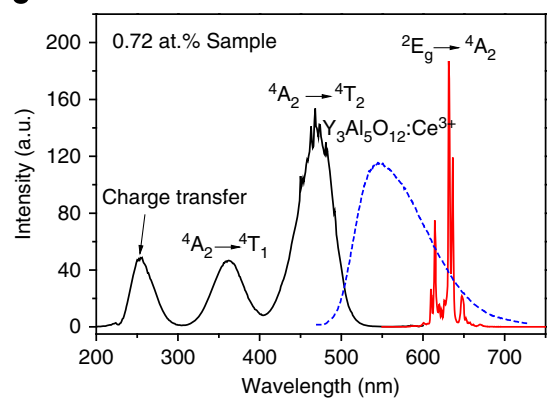

Figure 3 | Energy levels and optical spectra of $\mathbf{M n}^{\mathbf{4}}+$ emitters in fluoride phosphors. (a) Tanabe-Sugano energy diagram of a $3 d^{3}$ system in an octahedral crystal field. (b) Configurational coordinate diagram for $\mathrm{Mn}^{4+}$ ions in fluoride hosts. (c) Room temperature excitation and emission spectra of the $\mathrm{K}_{2} \mathrm{TiF}_{6}: \mathrm{Mn}^{4}+\left(0.72\right.$ at.\%) sample. The dashed line displays the emission spectrum of commercial $\mathrm{Y}_{3} \mathrm{Al}_{5} \mathrm{O}_{12}: \mathrm{Ce}^{3+}$ yellow phosphor. a.u., arbitrary unit.

spin-allowed ${ }^{4} \mathrm{~A}_{2} \rightarrow{ }^{4} \mathrm{~T}_{1}$ and ${ }^{4} \mathrm{~A}_{2} \rightarrow{ }^{4} \mathrm{~T}_{2}$ transitions, respectively. The full-width at half-maximum of the $468-\mathrm{nm}$ band is $\sim 50 \mathrm{~nm}$, which is even broader than that of blue-chip emission $(\sim 20 \mathrm{~nm})$. More importantly, as shown in Fig. 3c, the spectral overlap between excitation of $\mathrm{K}_{2} \mathrm{TiF}_{6}: \mathrm{Mn}^{4+}$ and emission of YAG:Ce ${ }^{3+}$ is negligibly small. Hence, serious re-absorption that often occurs between (oxy)nitride red phosphors and yellow (or green) phosphors in warm white LEDs can be avoided. The excitation band at $255 \mathrm{~nm}$ most likely originates from the charge transfer transition between $\mathrm{F}^{-}$and $\mathrm{Mn}^{4+}$ ions ${ }^{47}$. The red emission originating from the spin-forbidden ${ }^{2} \mathrm{E}_{\mathrm{g}} \rightarrow{ }^{4} \mathrm{~A}_{2}$ transition is composed of several sharp lines distributed in the spectral range of $610-650 \mathrm{~nm}$ with the strongest peak at $631.5 \mathrm{~nm}$ (Fig. 3c). Such an emission pattern differs greatly from those of (oxy)nitride red phosphors that usually exhibit considerable emissions over $650 \mathrm{~nm}$, and thus enables the fabrication of warm white LEDs with a higher LER.

A clear depiction of the electronic and vibronic energy diagram of $\mathrm{Mn}^{4+}$ in $\mathrm{K}_{2} \mathrm{TiF}_{6}$ host is essential for understanding the optical behaviours and application of this phosphor. The optical transitions of $\mathrm{Mn}^{4+}$ are sensitive to their local coordination, and the energy level splitting is determined by the local symmetry of the crystallographic site occupied by $\mathrm{Mn}^{4+}$ ions. When $\mathrm{Mn}^{4+}$ ions are doped into the crystal lattice of $\mathrm{K}_{2} \mathrm{TiF}_{6}$, they most probably substitute for $\mathrm{Ti}^{4}+$ ions with local site symmetry of $\mathrm{D}_{3 \mathrm{~d}}$ (ref. 36), descending from $\mathrm{O}_{\mathrm{h}}$. Based on group theory ${ }^{46}$, we first analysed the effect of this symmetry descending on energy level splitting. Then the spin-orbit interaction was taken into account. Detailed energy levels of $\mathrm{Mn}^{4+}$ at the site symmetry of $\mathrm{D}_{3 \mathrm{~d}}$ were deduced and plotted in Fig. 4a. It can be seen that both ${ }^{2} \mathrm{E}_{\mathrm{g}}$ and ${ }^{4} \mathrm{~A}_{2}$ states split into two sublevels due to spin-orbit interaction, and emissions from lower and upper sublevels of ${ }^{2} E_{g}$ were denoted as zero-phonon lines (ZPLs) of $R_{1}$ and $R_{2}$, respectively.

To further reveal the electronic and vibronic structure of $\mathrm{Mn}^{4+}$ in $\mathrm{K}_{2} \mathrm{TiF}_{6}$ crystal, we performed high-resolution PL measurement for the $\mathrm{K}_{2} \mathrm{TiF}_{6}: \mathrm{Mn}^{4+}(0.72$ at.\%) sample at $3-30 \mathrm{~K}$ (Fig. 4b). The extremely low temperature can avoid thermal broadening of the spectral bands for more reliable assignment of energy levels. At $30 \mathrm{~K}$, two weak and sharp emission peaks centred at 622.08 and $621.70 \mathrm{~nm}$, which were also observed in the excitation spectrum, and can be unquestionably assigned to $R_{1}$ and $R_{2}$ ZPLs of the ${ }^{2} \mathrm{E}_{\mathrm{g}} \rightarrow{ }^{4} \mathrm{~A}_{2}$ transition, respectively. As theoretically predicted in Fig. $4 \mathrm{a}$, four ZPLs are expected for the ${ }^{2} \mathrm{E}_{\mathrm{g}} \rightarrow{ }^{4} \mathrm{~A}_{2}$ transition due to double splitting of both ${ }^{2} \mathrm{E}_{\mathrm{g}}$ and ${ }^{4} \mathrm{~A}_{2}$ states. However, we cannot find such a pattern even in the enlarged region around the $R_{1}$ peak (inset of Fig. $4 \mathrm{~b}$ ), due most possibly to the extremely small crystal field splitting of ${ }^{4} \mathrm{~A}_{2}$ that is beyond the spectral resolution of our spectrometer. For instance, the energy level splitting of ${ }^{4} \mathrm{~A}_{2}$ in $\mathrm{Al}_{2} \mathrm{O}_{3}: \mathrm{Mn}^{4+}$ crystal was only $\sim 0.39 \mathrm{~cm}^{-1}$ (ref. 28). With further decreasing the temperature, the intensity of the $R_{2}$ line $(621.70 \mathrm{~nm})$ decreased gradually and almost disappeared at $3 \mathrm{~K}$ due to the thermal de-population from the upper sublevel of ${ }^{2} \mathrm{E}_{\mathrm{g}}$. The elimination of hot band emissions at $3 \mathrm{~K}$ enables more accurate identification of observed transitions.

The weak intensity of the ZPLs of ${ }^{2} \mathrm{E}_{\mathrm{g}} \rightarrow{ }^{4} \mathrm{~A}_{2}$ is ascribed to their magnetic dipole nature. However, the coupling of electronic transition with vibronic modes may introduce odd-parity crystal field terms into the wavefunctions of ${ }^{2} \mathrm{E}_{\mathrm{g}}$ and thus render the vibronic transition allowed for electric dipole radiation. Therefore, phonon-coupled vibronic transitions (that is, phonon sidebands) usually dominate the emissions of $\mathrm{Mn}^{4+}$. In Fig. $4 \mathrm{~b}$, besides the weak ZPLs, we can observe several intense emission lines ranging from 630 to $637 \mathrm{~nm}$, which originate from the electric dipole vibronic transitions induced by lattice vibrations with odd-parity. Consistently, at $3 \mathrm{~K}$, phonon sidebands arising from the upper sublevel of ${ }^{2} \mathrm{E}_{\mathrm{g}}$ nearly disappeared (indicated by the vertical dashed lines in Fig. $4 \mathrm{~b}$ ), and four sharp peaks centred at $630.81,631.98,634.68$ and $635.98 \mathrm{~nm}$ were well resolved, respectively. Meanwhile, a much broader vibronic emission band was observed at $\sim 647 \mathrm{~nm}$. According to the group theory, there are six fundamental internal vibronic modes $v_{1}\left(A_{1 g}\right), v_{2}\left(E_{g}\right), v_{3}\left(T_{1 u}\right), v_{4}\left(T_{1 u}\right), v_{5}\left(T_{2 g}\right)$ and $v_{6}\left(T_{2 u}\right)$ of octahedral group with symmetry of $\mathrm{O}_{\mathrm{h}}$. When the site symmetry of $\mathrm{Mn}^{4+}$ is reduced from $\mathrm{O}_{\mathrm{h}}$ to $\mathrm{D}_{3 \mathrm{~d}}$, the triply degenerate modes $v_{3}, v_{4}, v_{5}$ and $v_{6}$ will further split into a doubly degenerate mode and a non-degenerate mode ${ }^{48}$. The vibronic modes coupled to the ZPLs of ${ }^{2} \mathrm{E}_{\mathrm{g}} \rightarrow{ }^{4} \mathrm{~A}_{2}$ are antisymmetric $\mathrm{v}_{3}\left(\mathrm{~T}_{1 \mathrm{u}}\right), \mathrm{v}_{4}\left(\mathrm{~T}_{1 \mathrm{u}}\right)$ and $\mathrm{v}_{6}\left(\mathrm{~T}_{2 \mathrm{u}}\right)^{49}$. Specifically, the two peaks at 630.81 and $631.98 \mathrm{~nm}$ are assigned to the ${ }^{2} \mathrm{E}_{\mathrm{g}} \rightarrow{ }^{4} \mathrm{~A}_{2}+\mathrm{v}_{6}$ transitions, while the two peaks at 634.68 and $635.98 \mathrm{~nm}$ are attributed to the ${ }^{2} \mathrm{E}_{\mathrm{g}} \rightarrow{ }^{4} \mathrm{~A}_{2}+v_{4}$ transitions. The band at $\sim 647 \mathrm{~nm}$ is due to the ${ }^{2} \mathrm{E}_{\mathrm{g}} \rightarrow{ }^{4} \mathrm{~A}_{2}+v_{3}$ transition, and two relatively sharp peaks centred at 646.10 and $646.85 \mathrm{~nm}$ can be identified. Besides, abundant weak peaks in the range of $0-400 \mathrm{~cm}^{-1}$ shifting from the $R_{1}$ line were observed (Fig. 4c). These emissions mainly arise from the external lattice vibronic modes coupled to the ZPLs. All vibronic frequencies identified from the $3-\mathrm{K}$ emission spectra of $\mathrm{K}_{2} \mathrm{TiF}_{6}: \mathrm{Mn}^{4+}$ were found consistent with those derived from their Raman and infrared spectra (Supplementary Table 1$)^{34,48}$. These results present additional evidence for the occupation of $\mathrm{Mn}^{4+}$ ions in the sublattice of $\mathrm{Ti}^{4+}$.

Unlike the ${ }^{2} \mathrm{E}_{\mathrm{g}} \rightarrow{ }^{4} \mathrm{~A}_{2}$ transition, the excited transitions of ${ }^{4} \mathrm{~A}_{2} \rightarrow{ }^{4} \mathrm{~T}_{1},{ }^{4} \mathrm{~T}_{2}$ are spin-allowed, which exhibit broadband feature at RT as a result of the overlapping of multi-order phonon sidebands induced by strong electron-phonon interaction. To probe the fine structure of these bands, we measured the 
a

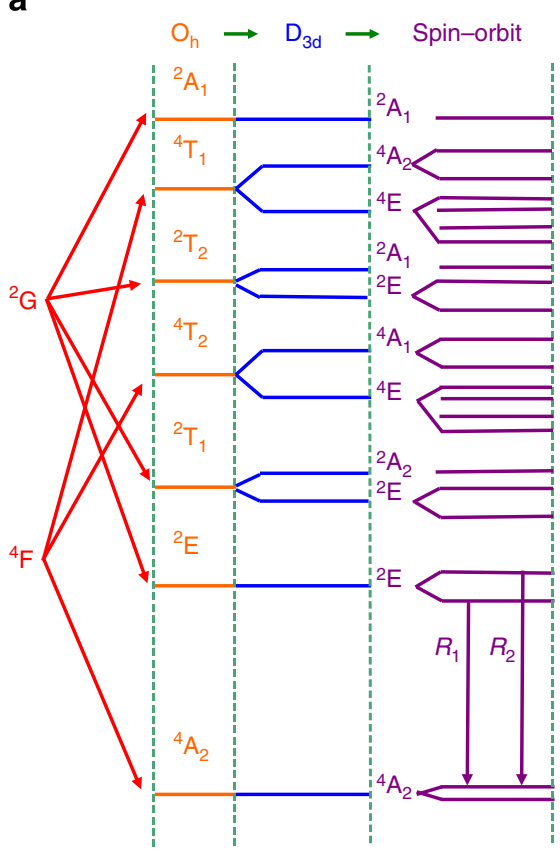

b

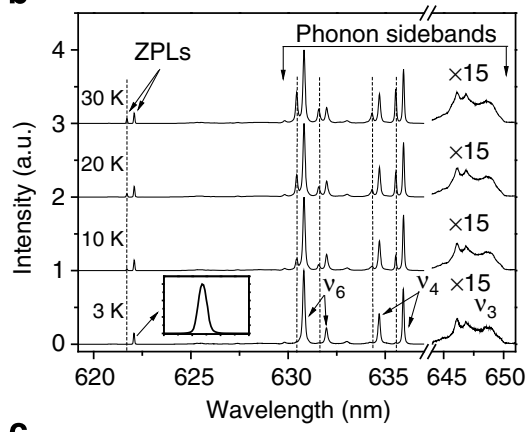

C

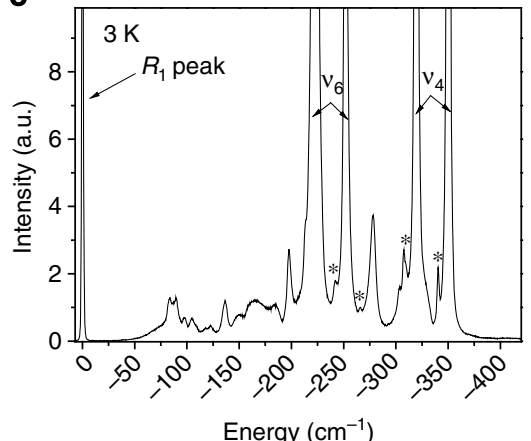

d

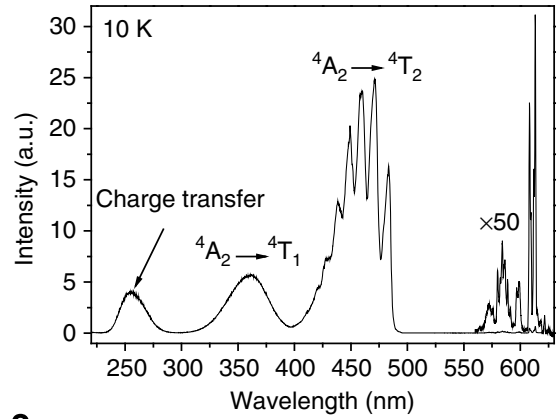

e

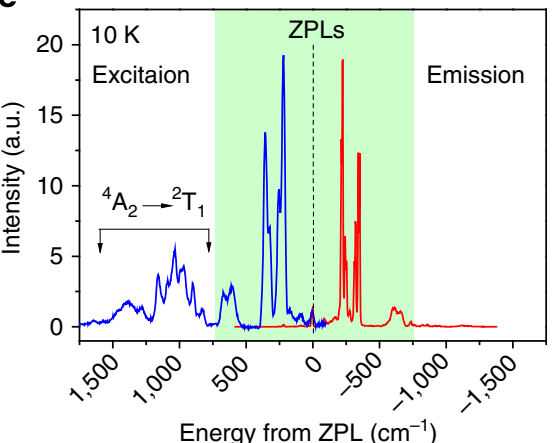

Figure 4 | High-resolution electronic and vibronic spectra of $\mathbf{K}_{\mathbf{2}} \mathbf{T i F}_{\mathbf{6}}: \mathbf{M n}{ }^{\mathbf{4}}+$ phosphor. (a) Deduced energy level splitting of $\mathrm{Mn}^{4+}$ ions at a crystallographic site of $\mathrm{D}_{3 d}$ symmetry. (b) High-resolution photoluminescence spectra of the $\mathrm{K}_{2} \mathrm{TiF}_{6}: \mathrm{Mn}^{4+}(0.72$ at.\%) sample measured at 3-30 K on 460-nm excitation. The inset shows the enlarged $R_{1}$ peak of the zero-phonon lines (ZPLs) at $3 \mathrm{~K}$. (c) Enlarged weak emission peaks at $3 \mathrm{~K}$ in the range of $0-400 \mathrm{~cm}^{-1}$ shifting from the $R_{1}$ line (the energy of $R_{1}$ is set to zero). The peaks indicated by asterisks are the residual emissions coupled to the upper sublevel of ${ }^{2} \mathrm{E}_{\mathrm{g}}$. (d) Excitation spectrum of the $\mathrm{K}_{2} \mathrm{TiF}_{6}: \mathrm{Mn}^{4+}(0.72$ at.\%) sample measured at $10 \mathrm{~K}$ when monitoring the dominant emission at $631 \mathrm{~nm}$. (e) Comparison of the vibronic excitations of ${ }^{4} \mathrm{~A}_{2} \rightarrow{ }^{2} \mathrm{~T}_{1}, \mathrm{E}_{\mathrm{g}}$ at $\sim 600 \mathrm{~nm}$ and the vibronic emissions of ${ }^{2} \mathrm{E}_{g} \rightarrow{ }^{4} \mathrm{~A}_{2}$ at $10 \mathrm{~K}$ (the energy of the $\mathrm{R}_{1}$ line is set to zero). The vertical dashed lines in $\mathbf{b}$ and $\mathbf{e}$ are the guidance for the eye. a.u., arbitrary unit.
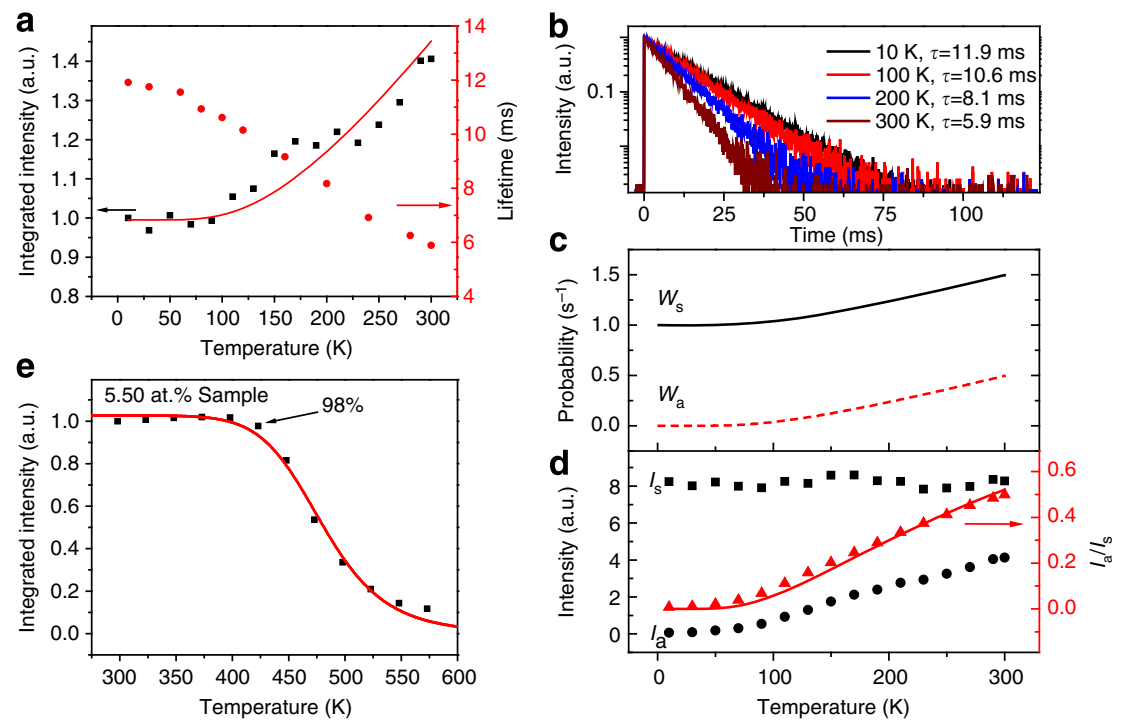

Figure $\mathbf{5}$ | Temperature-dependent photoluminescence $(\mathbf{P L})$ intensity and dynamics in $\mathbf{K}_{\mathbf{2}} \mathbf{T i F}_{\mathbf{6}}: \mathbf{M n} \mathbf{M}^{\mathbf{4}}$ phosphor. (a) Integrated red $\mathrm{PL}$ intensity due to the ${ }^{2} \mathrm{E}_{\mathrm{g}} \rightarrow{ }^{4} \mathrm{~A}_{2}$ transition and PL lifetime of the ${ }^{2} \mathrm{E}_{\mathrm{g}}$ state as a function of temperature (10-300 K) for the $\mathrm{K}_{2} \mathrm{TiF}_{6}: \mathrm{Mn}^{4}+(0.72$ at.\%) sample. The solid line represents the fitted result using the relation $W_{a b} \propto$ coth $(\hbar \omega / 2 \kappa T)$. (b) PL decays from the ${ }^{2} \mathrm{E}_{\mathrm{g}}$ state at $10-300 \mathrm{~K}$ for the $\mathrm{K}_{2} \mathrm{TiF}_{6}: \mathrm{Mn}^{4+}$ (0.72 at.\%) sample. (c) Simulated temperature-dependent Stokes $\left(W_{s}\right)$ and anti-Stokes $\left(W_{a}\right)$ transition probabilities of ${ }^{2} E_{g} \rightarrow{ }^{4} A_{2}$ by equations (1) and (2), respectively. (d) Measured PL intensities of $v_{6}$-mode-coupled Stokes $\left(I_{\mathrm{s}}\right)$ and anti-Stokes $\left(I_{\mathrm{a}}\right)$ transitions of ${ }^{2} \mathrm{E}_{\mathrm{g}} \rightarrow{ }^{4} \mathrm{~A}_{2}$ and the ratio of $I_{\mathrm{a}}$ to $I_{\mathrm{s}}$ as a function of temperature at $10-300 \mathrm{~K}$. The solid line represents the fitting result with the expression of $W_{\mathrm{a}}(T) / W_{\mathrm{s}}(T)$. (e) Integrated red $\mathrm{PL}$ intensity due to the ${ }^{2} E_{g} \rightarrow{ }^{4} A_{2}$ transition as a function of temperature (298-573 K) for the $\mathrm{K}_{2} \mathrm{TiF}_{6}: \mathrm{Mn}^{4+}$ (5.50 at.\%) sample. The solid line represents the fitting result with the expression of $I_{T} / I_{0}=\left[1+G \cdot \exp \left(-E_{a} / \kappa T\right)\right]^{-1}$. a.u., arbitrary unit. 
excitation spectra of the $\mathrm{K}_{2} \mathrm{TiF}_{6}: \mathrm{Mn}^{4+}(0.72$ at.\%) sample at $10 \mathrm{~K}$ (Fig. 4d). Particularly, the excitation band at $\sim 468 \mathrm{~nm}$ was observed to split into several sharp peaks separated by spacing of $\sim 550 \mathrm{~cm}^{-1}$. These peaks belong to the totally symmetric $v_{1}\left(\mathrm{~A}_{1 \mathrm{~g}}\right)$ vibronic progressions. The energy spacing of $\sim 550 \mathrm{~cm}^{-1}$ is somewhat smaller than the energy of $v_{1}\left(\sim 618 \mathrm{~cm}^{-1}\right)$. This discrepancy can be well explained by the fact that the vibronic frequencies derived from the excited state differ from those derived from the ground state, as the geometrical configurations are different in such two cases ${ }^{49}$. The energy levels of $3 \mathrm{~d}^{3}$ ions depend on the parameter $D_{\mathrm{q}}, B$ and $C$, where $D_{\mathrm{q}}$ is a parameter that characterizes the strength of the octahedral crystal field, while $B$ and $C$ are Racah parameters. We determined the values of these parameters from observed peak energies of ${ }^{4} \mathrm{~T}_{2},{ }^{4} \mathrm{~T}_{1}$ and ${ }^{2} \mathrm{E}_{\mathrm{g}}$ states in $\mathrm{K}_{2} \mathrm{TiF}_{6}: \mathrm{Mn}^{4+}, 2121,605$ and $4061 \mathrm{~cm}^{-1}$ for $D_{\mathrm{q}}, B$, and $C$, respectively. Based on these parameters, we calculated the energies of other states ${ }^{2} \mathrm{~T}_{1},{ }^{2} \mathrm{~A}_{1}$ and ${ }^{4} \mathrm{~T}_{1}$, located at 17,214, 36,316 and $28,698 \mathrm{~cm}^{-1}$, respectively (Supplementary Discussion) ${ }^{46,47}$. On the other hand, the energy level of ${ }^{2} \mathrm{~T}_{1}$ can be experimentally determined by comparing the vibronic excitations of ${ }^{4} \mathrm{~A}_{2} \rightarrow{ }^{2} \mathrm{~T}_{1}$, ${ }^{2} \mathrm{E}_{\mathrm{g}}$ at $\sim 600 \mathrm{~nm}$ with the vibronic emissions of ${ }^{2} \mathrm{E}_{\mathrm{g}} \rightarrow{ }^{4} \mathrm{~A}_{2}$ at $10 \mathrm{~K}$ (Fig. $4 \mathrm{~d}, \mathrm{e}$ ), that is, $17,107 \mathrm{~cm}^{-1}$, which is consistent with the calculated energy $\left(17,214 \mathrm{~cm}^{-1}\right)$ of ${ }^{2} \mathrm{~T}_{1}$. Note that the energy level of ${ }^{2} \mathrm{~T}_{1}$ had never been determined before this work.

Abnormal temperature-dependent PL intensity. It is well established that the PL intensity of most luminescent materials such as rare-earth-doped inorganic phosphors usually decreases with the rise of temperature due to the larger non-radiative transition probability at higher temperature. However, we observed an anomalous temperature-dependent PL behaviour in $\mathrm{K}_{2} \mathrm{TiF}_{6}: \mathrm{Mn}^{4+}$ phosphors (Supplementary Fig. 9). Typically, for the $\mathrm{K}_{2} \mathrm{TiF}_{6}: \mathrm{Mn}^{4+}(0.72$ at.\%) sample, the total PL intensity due to the ${ }^{2} \mathrm{E}_{\mathrm{g}} \rightarrow{ }^{4} \mathrm{~A}_{2}$ transition at $300 \mathrm{~K}$ was found to increase about $40 \%$ relative to that at $10 \mathrm{~K}$ (Fig. 5a). For comparison, PL decays from ${ }^{2} \mathrm{E}_{\mathrm{g}}$ by monitoring the $631-\mathrm{nm}$ emission at $10-300 \mathrm{~K}$ were measured (Supplementary Fig. 10). The PL lifetime of ${ }^{2} \mathrm{E}_{\mathrm{g}}$ by single exponential fit was found to decrease from $11.9 \mathrm{~ms}$ at $10 \mathrm{~K}$ to $5.9 \mathrm{~ms}$ at $300 \mathrm{~K}$ (Fig. 5b).

To reveal the mechanism for this abnormal phenomenon, we conducted a thorough analysis of the temperature-dependent behaviour of the vibronic emissions, which contribute dominantly to the PL intensity of $\mathrm{Mn}^{4+}$. The temperature-dependent Stokes $\left(W_{\mathrm{s}}(T)\right)$ and anti-Stokes $\left(W_{\mathrm{a}}(T)\right)$ radiative transition probabilities of vibronic emissions can be expressed as ${ }^{46}$ :

$$
\begin{aligned}
& W_{\mathrm{s}}(T)=D \cdot \frac{\exp (\hbar \omega / \kappa T)}{\exp (\hbar \omega / \kappa T)-1} \\
& W_{\mathrm{a}}(T)=D \cdot \frac{1}{\exp (\hbar \omega / \kappa T)-1}
\end{aligned}
$$

where $D$ is the proportional coefficient, $\hbar \omega$ is the energy of the coupled vibronic mode, and $\kappa$ is the Boltzmann constant. To demonstrate the effect of temperature on $W_{s}(T)$ and $W_{\mathrm{a}}(T)$, we chose the most intense $v_{6}$-mode-coupled vibronic emissions. Figure $5 c$ shows the simulated results of equations (1) and (2) in the temperature range of $0-300 \mathrm{~K}$ by setting $\hbar \omega=230 \mathrm{~cm}^{-1}$ (the average energy of $v_{6}$ mode) and $D=1$. Obviously, both Stokes and anti-Stokes transition probabilities increased with the rise of temperature. Correspondingly, the measured anti-Stokes emission intensity $I_{\mathrm{a}}$ increased rapidly with temperature, whereas the Stokes emission intensity $I_{\mathrm{s}}$ remained essentially unchanged (Fig. 5d). This can be attributed to the fact that the value of $W_{\mathrm{a}}(T)$ increased more rapidly than that of $W_{\mathrm{s}}(T)$ with the rise of temperature. To prove this, we fitted the data of $I_{\mathrm{a}} / I_{\mathrm{s}}$ with the expression of $W_{\mathrm{a}}(T) / W_{\mathrm{s}}(T)$ and observed a good agreement between experimental and fitted results (Fig. 5d). The PL lifetime of ${ }^{2} \mathrm{E}_{\mathrm{g}}$ is inversely proportional to the sum of radiative transition probability $W_{\mathrm{r}}(T)$ (namely $W_{\mathrm{s}}(T)+W_{\mathrm{a}}(T)$ ) and non-radiative transition probability $W_{\mathrm{n}}(T)$. For the $\mathrm{K}_{2} \mathrm{TiF}_{6}: \mathrm{Mn}^{4+}\left(0.72\right.$ at.\%) sample, $W_{\mathrm{n}}(T)$ is negligible at $10-300 \mathrm{~K}$ because the measured PL QY is $96 \%$ at $300 \mathrm{~K}$. Therefore, the decrease of the PL lifetime with the increase of temperature should be owing to the enhanced $W_{\mathrm{r}}(T)$ at elevated temperature (Fig. 5a). It should be noted that this mechanism is completely different from that in other luminescent materials, which are usually caused by increasing non-radiative transition probability with the rise of temperature.

The PL intensity is proportional to the product of absorbed photons and PL quantum efficiency. Thus the effect of temperature on these two factors determines the temperaturedependent PL intensity. The quantum efficiency $\eta$ of ${ }^{2} \mathrm{E}_{\mathrm{g}}$ can be expressed as $W_{\mathrm{r}}(T) /\left(W_{\mathrm{r}}(T)+W_{\mathrm{n}}(T)\right)$. As $W_{\mathrm{n}}(T)$ is negligible for the $\mathrm{K}_{2} \mathrm{TiF}_{6}: \mathrm{Mn}^{4+}(0.72$ at.\%) sample at $10-300 \mathrm{~K}$, the value of $\eta$ can be approximated as a constant close to unit and it has no influence on the PL intensity with the change of temperature at $10-300 \mathrm{~K}$. On the other hand, the transition probability $W_{\mathrm{ab}}$ of the vibronic absorption of ${ }^{4} \mathrm{~A}_{2} \rightarrow{ }^{4} \mathrm{~T}_{2}$ is also temperaturedependent and proportional to $\operatorname{coth}(\hbar \omega / 2 \kappa T)^{46}$. When taking these into account, the fitted PL intensity as a function of temperature agrees well with the observation (Fig. 5a). Hence, we infer that the main contribution to the incremental PL intensity at elevated temperature is ascribed to the increased absorption of excitation light by the sample. As expected, such an abnormal PL intensity behaviour should be concentration-independent. To prove this, we further measured the temperature-dependent PL intensities at $10-300 \mathrm{~K}$ for the 6.50 at. $\%$ sample, which displays a similar increase $(\sim 40 \%)$ in the PL intensity (Supplementary Fig. 11).

The working temperature of phosphors in LEDs could be much higher above RT. Usually, the remained PL intensity at $150^{\circ} \mathrm{C}$ with respect to that at RT is used to evaluate the thermal stability of phosphors. The PL intensity of the $\mathrm{K}_{2} \mathrm{TiF}_{6}: \mathrm{Mn}^{4+}$ (5.50 at.\%) sample at $125^{\circ} \mathrm{C}$ even increased about $2 \%$ when compared to that at $25^{\circ} \mathrm{C}$, as a result of the enhanced absorption as observed at $10-300 \mathrm{~K}$. At $150^{\circ} \mathrm{C}$, the relative PL intensity of the sample remains $98 \%$ of that at $25^{\circ} \mathrm{C}$ (Fig. 5e), showing clearly a better thermal stability than that of YAG:Ce ${ }^{3+}$ phosphor $^{50}$. However, above $175^{\circ} \mathrm{C}$, the emission intensity decreased rapidly due to the markedly increased non-radiative transition probability with further increase of temperature. We fitted the curve with the expression of $I_{\mathrm{T}} / I_{0}=\left[1+G \cdot \exp \left(-E_{\mathrm{a}} / \kappa T\right)\right]^{-1}$, where $I_{0}$ (intensity at $T=0), G$ and activation energy $E_{a}$ are refined variables ${ }^{51}$. The $\mathrm{K}_{2} \mathrm{TiF}_{6}: \mathrm{Mn}^{4+}(5.50$ at.\%) phosphor has an activation energy $\left(E_{\mathrm{a}}\right)$ of $\sim 0.70 \mathrm{eV}$, which is 3 times as high as that of nitride compounds $(\sim 0.25 \mathrm{eV})^{52}$. This verifies the excellent thermal stability of $\mathrm{K}_{2} \mathrm{TiF}_{6}: \mathrm{Mn}^{4+}$ phosphors.

Fabrication and performance of warm white LEDs. To evaluate the device performance for the synthesized $\mathrm{K}_{2} \mathrm{TiF}_{6}: \mathrm{Mn}^{4+}$ phosphor, we fabricated white LEDs with various CCTs by combining blue chips $(455 \mathrm{~nm}), \mathrm{YAG}: \mathrm{Ce}^{3+}$ yellow (YAG04, Intematix) or aluminate green phosphors (GAL535, Intematix), and the $\mathrm{K}_{2} \mathrm{TiF}_{6}: \mathrm{Mn}^{4+}$ (5.50 at.\%) red phosphor. The chromaticity coordinates of three typical LEDs with CCTs of 2,783, 3,556 and $5,954 \mathrm{~K}$ under a drive current of $60 \mathrm{~mA},(0.4569,0.4158)$, $(0.3997,0.3821)$ and $(0.3224,0.3416)$, are marked in CIE 1931 colour spaces, respectively, and all three colour points are laid on or close to the black body locus (Fig. 6a). Photographs of the as-fabricated LEDs and three lighted ones are shown in Fig. 6b-e. 


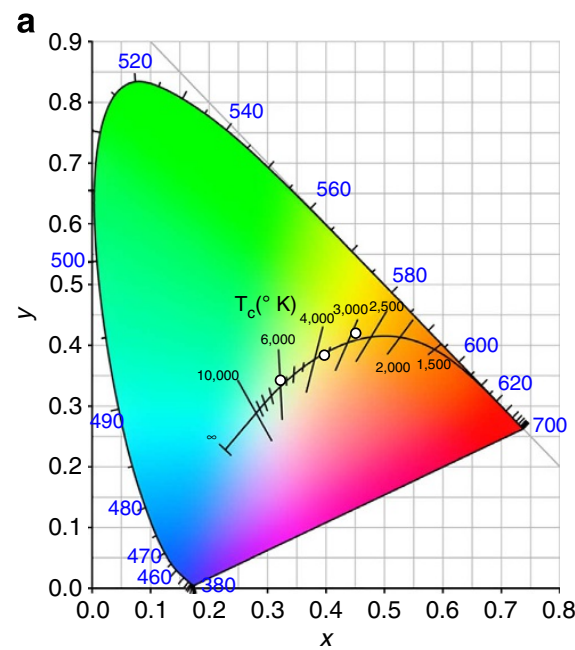

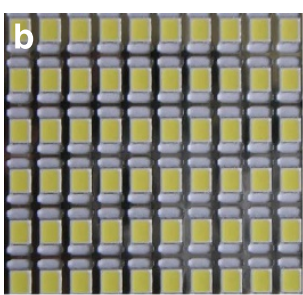
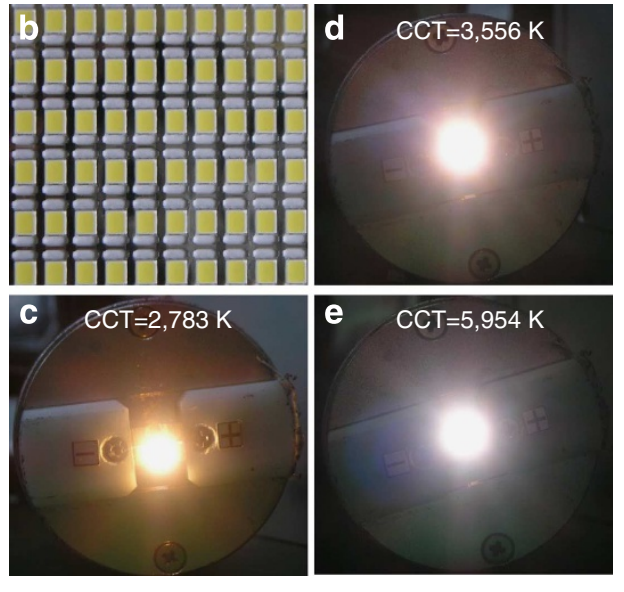

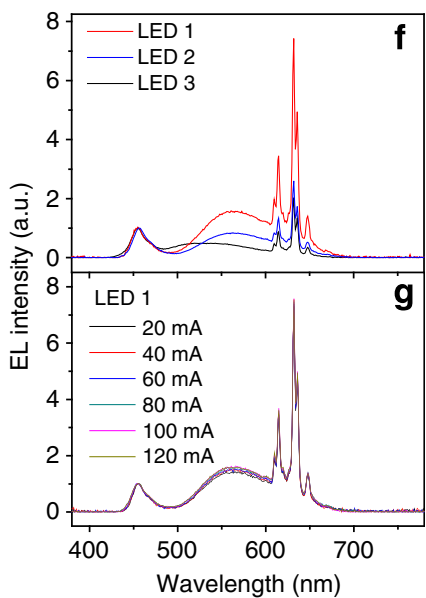

Figure 6 | Device performance of fabricated white LEDs based on $\mathbf{K}_{\mathbf{2}} \mathbf{T i F}_{\mathbf{6}}: \mathbf{M n} \mathbf{4}^{\mathbf{4}}$ red phosphor. (a) The chromaticity coordinates of three typical LEDs with correlated colour temperatures (CCTs) of 2,783, 3,556 and 5,954 K under a drive current of $60 \mathrm{~mA}$ in Commission Internationale de l'Éclairage (CIE) 1931 colour spaces. Photographs of the (b) as-fabricated LEDs and lighted ones with CCTs of (c) 2,783, (d) 3,556 and (e) 5,954 K, respectively. Electroluminescent (EL) spectra of (f) the three LEDs under 60-mA drive current and (g) LED 1 under various drive currents. All the spectra were normalized at the peak intensity at $455 \mathrm{~nm}$. a.u., arbitrary unit.

Table 2 | Important photoelectric parameters for three typical LEDs with different correlated colour temperatures (CCTs).

\begin{tabular}{|c|c|c|c|c|c|c|c|c|}
\hline Devices & Phosphor blend & CCT (K) & $R_{\mathrm{a}}$ & $R_{9}$ & \multicolumn{2}{|c|}{ Chromaticity coordinate } & Current (mA) & Efficacy $\left(\operatorname{Im~} \mathbf{W}^{-1}\right)$ \\
\hline \multirow[t]{5}{*}{ LED 1} & YAG04 + $\mathrm{K}_{2} \mathrm{TiF}_{6}: \mathrm{Mn}^{4+}$ & 2,748 & 85 & 53 & 0.4575 & 0.4124 & 20 & 124 \\
\hline & & 2,783 & 83 & 45 & 0.4569 & 0.4158 & $60^{*}$ & 110 \\
\hline & & 2,821 & 83 & 47 & 0.4539 & 0.4152 & 80 & 99 \\
\hline & & 2,820 & 83 & 44 & 0.4550 & 0.4172 & 100 & 93 \\
\hline & & 2,833 & 84 & 46 & 0.4534 & 0.4158 & 120 & 88 \\
\hline
\end{tabular}

In accordance with the decrease of CCT, a pronounced warmer tone of the emitting light was observed, owing to the incremental red light component in the emission spectrum of LED. Electroluminescent spectra of the three LEDs reconfirm the sharp emission lines of $\mathrm{Mn}^{4+}$ in $\mathrm{K}_{2} \mathrm{TiF}_{6}$ phosphor and more red emitting component with the lower CCT (Fig. 6f). Table 2 compares the important photoelectric parameters such as CCT, CRI and luminous efficacy for the three LEDs. It is well known that a commercial white LED using a single YAG: $\mathrm{Ce}^{3+}$ phosphor generally has a low CRI and high CCT, typically, $R_{\mathrm{a}}<70$ and CCT $>5,000 \mathrm{~K}$ (ref. 53), which is unsuitable for indoor lighting. By adding $\mathrm{K}_{2} \mathrm{TiF}_{6}: \mathrm{Mn}^{4+}$ red phosphor into the devices, warm white LEDs with $R_{\mathrm{a}}>80$ and CCT $<4,000 \mathrm{~K}$ can be readily used for indoor lighting (LEDs 1 and 2, Table 2). Specifically, all the R9 values are positive, which suggest good rendition of the strong red colour. The luminous efficacies of these two LEDs are 110 and $116 \mathrm{~lm} \mathrm{~W}^{-1}$ under $60-\mathrm{mA}$ drive current, respectively, which are much higher than that of the counterparts using nitride red phosphors (68 $1 \mathrm{~m} \mathrm{~W}^{-1}$ under $50-\mathrm{mA}$ drive current) previously reported $^{54}$. To the best of our knowledge, the luminous efficacy of LED $2\left(116 \mathrm{~lm} \mathrm{~W} \mathrm{~m}^{-1}, \mathrm{CCT}=3,556 \mathrm{~K}\right)$ is the highest among warm white LEDs achieved on commercial blue chips in the literature. For LED 3, cool white light $(\mathrm{CCT}=5,954 \mathrm{~K})$ with an ultrahigh CRI of $R_{\mathrm{a}}=95$ can be generated, where the phosphor blend is composed of aluminate green and $\mathrm{K}_{2} \mathrm{TiF}_{6}: \mathrm{Mn}^{4+}$ red phosphors.
To evaluate the current-dependent LED performance, we measured the luminous efficacies of the three LEDs under various drive currents of 20,40,60 (the rated current of blue chip), 80, 100 and $120 \mathrm{~mA}$, respectively. The luminous efficacy of LED 1 was found to increase gradually from 110 to $124 \mathrm{~lm} \mathrm{~W}-1$ when the drive current decreased from 60 to $20 \mathrm{~mA}$ (Table 2). This is owing to the larger external quantum efficiency of the blue chip under lower drive current density ${ }^{55}$. Likewise, the luminous efficacies of LED 2 and 3 under $20 \mathrm{~mA}$ drive current reached as high as 132 and $135 \mathrm{~lm} \mathrm{~W}^{-1}$, respectively.

Small colour fluctuation under varied excitation powers is crucial for the long-term service of LEDs. We found that the electroluminescent spectra of LED 1 under different drive currents remained essentially the same (Fig. 6g), indicative of very small colour fluctuation. The slight variation of the chromaticity coordinate, merely 0.0054 for CIE- $x$ and 0.0048 for CIE- $y$, respectively, reconfirms the negligible colour fluctuation in LED 1. Theoretically, the PL intensity saturation might occur more likely in $\mathrm{K}_{2} \mathrm{TiF}_{6}: \mathrm{Mn}^{4+}$ phosphor than in $\mathrm{Ce}^{3+}$ - and $\mathrm{Eu}^{2+}$-activated phosphors due to the much longer PL lifetime of $\mathrm{Mn}^{4+}(5.70 \mathrm{~ms})$ than that of $\mathrm{Ce}^{3+}$ and $\mathrm{Eu}^{2+}$ (approximately tens of nanoseconds). Fortunately, as demonstrated in Fig. 6g, no PL intensity saturation was observed until the drive current reached $120 \mathrm{~mA}$ in LED 1, which indicates the potential use of our phosphors in high power LEDs. 


\section{Discussion}

In summary, we have developed a novel cation exchange strategy for the synthesis of micrometre-sized $\mathrm{K}_{2} \mathrm{TiF}_{6}: \mathrm{Mn}^{4+}$ phosphor with an unusually fast rate, where $67 \%$ of the $\mathrm{Mn}^{4+}$ ions in the precursor solution were found to substitute for the $\mathrm{Ti}^{4+}$ ions within 3 min. The synthesized $\mathrm{K}_{2} \mathrm{TiF}_{6}: \mathrm{Mn}^{4+}$ red phosphor shows an extremely high PL QY up to $98 \%$, which is superior to those of rare-earth (oxy)nitride red phosphors such as $\mathrm{Ca}-\alpha$-SiAlON: $\mathrm{Eu}^{2+}(\mathrm{QY}=70.5 \%)$ and $\mathrm{CaAlSiN} 3 \mathrm{~B}: \mathrm{Ce}^{3+}(\mathrm{QY}=80 \%)^{18,19}$. The proposed approach shows the advantages of higher production yield, much less HF solution consumption and shorter preparation time than those previously reported, thus paving the way for mass production of this phosphor. Furthermore, we have demonstrated the universality of this approach through the successful syntheses of other $\mathrm{Mn}^{4+}$-activated fluoride phosphors such as $\mathrm{K}_{2} \mathrm{SiF}_{6}: \mathrm{Mn}^{4+}, \mathrm{NaGdF}_{4}: \mathrm{Mn}^{4+}$ and $\mathrm{NaYF}_{4}: \mathrm{Mn}^{4+}$.

More importantly, the $\mathrm{K}_{2} \mathrm{TiF}_{6}: \mathrm{Mn}^{4+}$ phosphor exhibited the most intense excitation band at $\sim 468 \mathrm{~nm}$ with a bandwidth of $\sim 50 \mathrm{~nm}$, which is perfect for blue-chip excitation. The spectral overlap between this excitation band and the emission band of YAG: $\mathrm{Ce}^{3+}$ is negligible, hence the problem of re-absorption that occurred in LEDs based on (oxy)nitride red phosphors can be avoided. Furthermore, the phosphor exhibited sharp red emissions at $\sim 630 \mathrm{~nm}$, thereby rendering a higher LER in warm white LEDs as compared to (oxy)nitride red phosphors that show substantial emission spreading into deep red spectral region. By means of low-temperature high-resolution spectroscopy, the detailed electronic/vibronic structure of $\mathrm{Mn}^{4+}$ ions in $\mathrm{K}_{2} \mathrm{TiF}_{6}$ host has been elaborated. The observed energy level splittings of $\mathrm{Mn}^{4+}$, with a crystallographic site symmetry of $\mathrm{D}_{3 \text { d }}$, were found in good agreement with that calculated theoretically, which provides additional evidence for the residence of $\mathrm{Mn}^{4+}$ in the sublattice of $\mathrm{Ti}^{4+}$ through cation exchange. Based on $\mathrm{PL}$ dynamics, PL QY and theoretical analysis, we have revealed the mechanism for abnormal dependence of PL intensity on the temperature in $\mathrm{K}_{2} \mathrm{TiF}_{6}: \mathrm{Mn}^{4+}$ (an increase of $\sim 40 \%$ in the PL intensity at $300 \mathrm{~K}$ relative to that at $10 \mathrm{~K}$ ). It has been corroborated that the increased absorption of excitation light by the sample contributed dominantly to the incremental PL intensity with the rise of temperature.

Finally, by integrating this phosphor with commercial YAG: $\mathrm{Ce}^{3+}$ yellow phosphor and $455-\mathrm{nm}$ blue chip, we have fabricated a warm white LED with high CRI $\left(R_{\mathrm{a}}=81\right)$, low CCT $(3,556 \mathrm{~K})$ and a record-high luminous efficiency of $116 \mathrm{~lm} \mathrm{~W}^{-1}$ under rated $60-\mathrm{mA}$ drive current. The LEDs also show excellent chromaticity coordinate stability with the drive current varied from 20 to $120 \mathrm{~mA}$. These findings show great promise of $\mathrm{K}_{2} \mathrm{TiF}_{6}: \mathrm{Mn}^{4+}$ as commercial red phosphor in warm white LEDs, and open up new avenues for the exploration of novel non-rareearth red emitting phosphors.

\section{Methods}

Chemicals and materials. $\mathrm{K}_{2} \mathrm{TiF}_{6}(\geq 99.95 \%), \mathrm{K}_{2} \mathrm{SiF}_{6}(\geq 99.999 \%)$ and $\mathrm{HF}$ solution (49 wt.\%, $\geq 99.99998 \%$ metals basis) were purchased from Aladdin Chemistry, China. The $\mathrm{K}_{2} \mathrm{MnF}_{6}$ crystals were prepared based on Bode's method ${ }^{56}$. All the chemicals were used directly without further purification.

\section{Synthesis of $\mathbf{K}_{\mathbf{2}} \mathbf{T i F}_{\mathbf{6}}: \mathbf{M n} \mathbf{4}^{\mathbf{4}}$ phosphor. A cation exchange approach was} employed for the synthesis of $\mathrm{K}_{2} \mathrm{TiF}_{6}: \mathrm{Mn}^{4+}$ microcrystals. To demonstrate this, we described the preparation procedure for the $\mathrm{K}_{2} \mathrm{TiF}_{6}: \mathrm{Mn}^{4+}(0.72$ at.\%) sample. Typically, $0.0360 \mathrm{~g}$ of $\mathrm{K}_{2} \mathrm{MnF}_{6}$ powders were first dissolved in $1.8 \mathrm{ml}$ of HF solution (49 wt.\%). Then, the obtained solution was mixed with $4.9640 \mathrm{~g}$ of $\mathrm{K}_{2} \mathrm{TiF}_{6}$ powders under stirring for $20 \mathrm{~min}$ to form a uniform muddy mixture, which was subjected to drying at $70^{\circ} \mathrm{C}$ for $3 \mathrm{~h}$ in an oven. The final product showed a uniform yellow tint under natural light illumination. Other four samples with $\mathrm{Mn}^{4+}$ concentrations of $1.40,2.10,5.50$ and 6.50 at.\% were prepared following the same procedure. A proof-of-concept experiment was designed to reveal the occurrence of cation exchange in the above approach. First, $0.0452 \mathrm{~g}$ of $\mathrm{K}_{2} \mathrm{MnF}_{6}$ powders were dissolved in excess of HF solution ( 49 wt.\%, $0.8 \mathrm{ml}$ ), which afforded a clear brown solution. Then, $0.7548 \mathrm{~g}$ of $\mathrm{K}_{2} \mathrm{TiF}_{6}$ powders were added to the solution (the atom percent of $\mathrm{Mn}$ is $5.50 \%$ ). The quantity of the added $\mathrm{K}_{2} \mathrm{TiF}_{6}$ powders was small to maintain good fluidity of the solution, thus facilitating the separation of the products by vacuum filtration. Finally, after cation exchange for 3 min under stirring, the undissolved powders in the solution $(0.5796 \mathrm{~g})$ were isolated instantly through vacuum filtration, followed by drying at $70^{\circ} \mathrm{C}$ for $3 \mathrm{~h}$. The colour of the mixture solution was observed to change from brown to light-yellow. Accordingly, the colour of the powders changed from white to yellow after cation exchange.

Structural and optical characterization. Powder XRD patterns of the $\mathrm{K}_{2} \mathrm{TiF}_{6}: \mathrm{Mn}^{4+}$ samples were measured by an X-ray diffractometer (DMAX $2500 \mathrm{PC}$, Rigaku) at an interval of $0.02^{\circ}$ with the speed of $2^{\circ} \mathrm{min}^{-1}$ with $\mathrm{Cu} \mathrm{K} \alpha 1$ radiation $(\lambda=0.154187 \mathrm{~nm})$. The unit cell refinements were accomplished by the JADE software. The morphologies of the samples were characterized by a scanning electron microscope (JSM-6700F). Scanning transmission electron microscopy and energy dispersive spectroscopy analyses were performed on a TECNAI G ${ }^{2}$ F20 TEM operated at $200 \mathrm{kV}$. Compositional analyses were performed using an ICP-AES (Ultima2). The RT excitation and emission spectra and PL decays were measured with an Edinburgh Instrument FLS920 spectrometer equipped with both continuous $(450 \mathrm{~W})$ and microsecond pulsed xenon $(\mathrm{Xe})$ lamps. For temperaturedependent experiments at $10-300 \mathrm{~K}$, the samples were mounted on an optical cryostat (10-350 K, DE202, Advanced Research Systems). The high-resolution spectral measurements at 3-30 K were carried out using a monochromator with 1-m focal length (1,000 M, Jobin-Yvon) equipped with a photomultiplier tube (R943-02, Hamamatsu), and the samples were mounted on an optical cryostat (3-300 K, SHI-950, Janis Research). To investigate the PL thermal stability at $298-573 \mathrm{~K}$, the samples were placed on a thermal stage (77-873 K, THMS 600 , Linkam Scientific Instruments) and a fibre coupled spectrometer (QE 65000, Ocean Optics) was used to record the emission spectra of the sample excited by a $455-\mathrm{nm}$ diode chip. For PL QY measurement, the samples were put inside an optical integrating sphere coupled to the FLS 920 spectrometer. A standard tungsten halogen lamp was used to correct the optical response of the instrument.

LEDs fabrication and performance measurement. White LEDs with various CCTs were fabricated by combining blue chips $(455 \mathrm{~nm}, 180 \mathrm{~mW}, 60 \mathrm{~mA}$, Tek core), YAG: $\mathrm{Ce}^{3+}$ yellow (YAG04, Intematix) or aluminate green phosphors (GAL535, Intematix) and the $\mathrm{K}_{2} \mathrm{TiF}_{6}: \mathrm{Mn}^{4+}$ (5.50 at. \%) red phosphor. The blue chip was first fixed on the bottom of a reflector. The phosphors were mixed with silicone thoroughly and the obtained phosphor-silicone mixture was coated on the surface of the LED chips to produce white LEDs. The photoelectric properties of the fabricated devices were measured by an integrating sphere spectroradiometer system (LHS-1000, Everfine). The LEDs were operated at $3.0 \mathrm{~V}$ with various drive currents of $20,40,60,80,100$ and $120 \mathrm{~mA}$, respectively. The spectral power distributions of the LEDs were measured by a corrected spectrometer to calculate their values of CCT and CRI (ref. 57). The luminous efficacy was measured as the ratio of luminous flux $(\mathrm{lm})$ output to the input electrical power $(\mathrm{W})$ of the LEDs. The CCTs of three typical fabricated LEDs were 2,783 (LED 1), 3,556 (LED 2) and $5,954 \mathrm{~K}$ (LED 3) under a drive current of $60 \mathrm{~mA}$, respectively. For LEDs 1 and 2, the phosphor blend was composed of YAG04 yellow and $\mathrm{K}_{2} \mathrm{TiF}_{6}: \mathrm{Mn}^{4+}(5.50$ at. \%) red phosphors. For LED 3, the phosphor blend was composed of GAL535 green and $\mathrm{K}_{2} \mathrm{TiF}_{6}: \mathrm{Mn}^{4+}(5.50$ at.\%) red phosphors. The mass percentages of red phosphor in the phosphor blends were 70, 61 and 50\% for LEDs 1-3, respectively.

\section{References}

1. Žukauskas, A., Shur, M. S. \& Gaska, R. Introduction to Solid State Lighting (John Wiley \& Sons, Inc., 2002).

2. Humphreys, C. J. Solid-state lighting. MRS Bull. 33, 459-470 (2008).

3. Schubert, E. F. \& Kim, J. K. Solid-state light sources getting smart. Science 308, 1274-1278 (2005).

4. Xie, R. -J., Li, Y. Q., Hirosaki, N. \& Yamamoto, H. Nitride Phosphors and Solid State Lighting (Taylor \& Francis, 2011).

5. Daicho, H. et al. A novel phosphor for glareless white light-emitting diodes. Nat. Commun 3, 1132 (2012).

6. Sun, C. -Y. et al. Efficient and tunable white-light emission of metal-organic frameworks by iridium-complex encapsulation. Nat. Commun. 4, 2717 (2013)

7. Im, W. B. et al. Efficient and color-tunable oxyfluoride solid solution phosphors for solid-state white lighting. Adv. Mater. 23, 2300-2305 (2011).

8. Chen, W. -T., Sheu, H. -S., Liu, R. -S. \& Attfield, J. P. Cation-size-mismatch tuning of photoluminescence in oxynitride phosphors. J. Am. Chem. Soc. 134, 8022-8025 (2012).

9. Dai, Q., Foley, M. E., Breshike, C. J., Lita, A. \& Strouse, G. F. Ligand-passivated $\mathrm{Eu}: \mathrm{Y}_{2} \mathrm{O}_{3}$ nanocrystals as a phosphor for white light emitting diodes. J. Am. Chem. Soc. 133, 15475-15486 (2011)

10. Duan, C. J., Otten, W. M., Delsing, A. C. A. \& Hintzen, H. T. Photoluminescence properties of $\mathrm{Eu}^{2+}$-activated sialon S-phase $\mathrm{BaAlSi}_{5} \mathrm{O}_{2} \mathrm{~N}_{7}$. J. Alloy. Compd. 461, 454-458 (2008) 
11. Park, W. B., Singh, S. P., Yoon, C. \& Sohn, K. -S. Combinatorial chemistry of oxynitride phosphors and discovery of a novel phosphor for use in light emitting diodes, $\mathrm{Ca}_{1.5} \mathrm{Ba}_{0.5} \mathrm{Si}_{5} \mathrm{~N}_{6} \mathrm{O}_{3}: \mathrm{Eu}^{2+}$. J. Mater. Chem. C 1, 1832-1839 (2013).

12. Park, W. B., Singh, S. P. \& Sohn, K. S. Discovery of a phosphor for LED applications and its structural determination; $\mathrm{Ba}(\mathrm{Si}, \mathrm{Al})_{5}(\mathrm{O}, \mathrm{N})_{8}: \mathrm{Eu}^{2+}$. J. Am. Chem. Soc. 136, 2363-2373 (2014).

13. Yeh, C. -W. et al. Origin of thermal degradation of $\mathrm{Sr}_{2-\mathrm{x}} \mathrm{Si}_{5} \mathrm{~N}_{8}: \mathrm{Eu}_{\mathrm{x}}$ phosphors in air for light-emitting diodes. J. Am. Chem. Soc. 134, 14108-14117 (2012).

14. Xie, R. -J. \& Hirosaki, N. Silicon-based oxynitride and nitride phosphors for white LEDs - A review. Sci. Technol. Adv. Mat. 8, 588-600 (2007).

15. Hecht, C. et al. $\mathrm{SrAlSi}_{4} \mathrm{~N}_{7}: \mathrm{Eu}^{2+}$-a nitridoalumosilicate phosphor for warm white light (pc)LEDs with edge-sharing tetrahedra. Chem. Mater. 21, 1595-1601 (2009).

16. Duan, C. J. et al. Preparation, electronic structure, and photoluminescence properties of $\mathrm{Eu}^{2+}$ and $\mathrm{Ce}^{3+} / \mathrm{Li}^{+}$-activated alkaline earth silicon nitride $\mathrm{MSiN}_{2}(\mathrm{M}=\mathrm{Sr}, \mathrm{Ba})$. Chem. Mater. 20, 1597-1605 (2008).

17. Park, W. B., Singh, S. P., Yoon, C. \& Sohn, K. S. Eu ${ }^{2+}$ luminescence from 5 different crystallographic sites in a novel red phosphor, $\mathrm{Ca}_{15} \mathrm{Si}_{20} \mathrm{O}_{10} \mathrm{~N}_{30}: \mathrm{Eu}^{2+}$. J. Mater. Chem. 22, 14068-14075 (2012).

18. Yamada, S., Emoto, H., Ibukiyama, M. \& Hirosaki, N. Properties of SiAlON powder phosphors for white LEDs. J. Eur. Ceram. Soc. 32, 1355-1358 (2012).

19. Li, Y. Q., Hirosaki, N., Xie, R. J., Takeda, T. \& Mitomo, M. Yellow-orangeemitting $\mathrm{CaAlSiN}_{3}: \mathrm{Ce}^{3+}$ phosphor: structure, photoluminescence, and application in white LEDs. Chem. Mater. 20, 6704-6714 (2008).

20. Uheda, K. et al. Luminescence properties of a red phosphor, $\mathrm{CaAlSiN}_{3}: \mathrm{Eu}^{2+}$, for white light-emitting diodes. Electrochem. Solid ST 9, H22-H25 (2006).

21. Piao, X. et al. Preparation of $\mathrm{CaAlSiN}_{3}: \mathrm{Eu}^{2+}$ phosphors by the self-propagating high-temperature synthesis and their luminescent properties. Chem. Mater. 19, 4592-4599 (2007).

22. Tan, S. T., Sun, X. W., Demir, H. V. \& DenBaars, S. P. Advances in the LED materials and architectures for energy-saving solid-state lighting toward 'lighting revolution'. IEEE Photon. J. 4, 613-619 (2012).

23. Solid-State Lighting Research and Developing: Multi-Year Program Plan, Available at http://apps1.eere.energy.gov/buildings/publications/pdfs/ssl/ ssl_mypp2012_web.pdf (2012).

24. Piquette, A. P., Hannah, M. E. \& Mishra, K. C. An investigation of selfabsorption and corresponding spectral shift in phosphors. ECS Trans. 41, 1-9 (2012).

25. Sakuma, K. et al. Warm-white light-emitting diode with yellowish orange SiAlON ceramic phosphor. Opt. Lett. 29, 2001-2003 (2004).

26. Yen, W. M., Shionoya, S. \& Yamamoto, H. Phosphor Handbook (CRC Press, 2007).

27. Thorington, L. Temperature dependence of the emission of an improved manganese-activated magnesium germanate phosphor. J. Opt. Soc. Am. 40, 579-583 (1950).

28. Geschwind, S., Kisliuk, P., Klein, M. P., Remeika, J. P. \& Wood, D. L. Sharp-line fluorescence, electron paramagnetic resonance, and thermoluminescence of $\mathrm{Mn}^{4+}$ in alpha- $\mathrm{Al}_{2} \mathrm{O}_{3}$. Phys. Rev. 126, 1684-1686 (1962).

29. Brik, M. G., Srivastava, A. M. \& Avram, N. M. Comparative analysis of crystal field effects and optical spectroscopy of six-coordinated $\mathrm{Mn}^{4+}$ ion in the $\mathrm{Y}_{2} \mathrm{Ti}_{2} \mathrm{O}_{7}$ and $\mathrm{Y}_{2} \mathrm{Sn}_{2} \mathrm{O}_{7}$ pyrochlores. Opt. Mater. 33, 1671-1676 (2011).

30. Paulusz, A. G. Efficient Mn(IV) emission in fluorine coordination. J. Electrochem. Soc. 120, 942-947 (1973).

31. Sekiguchi, D., Nara, J. \& Adachi, S. Photoluminescence and Raman scattering spectroscopies of $\mathrm{BaSiF}_{6}: \mathrm{Mn}^{4+}$ red phosphor. J. Appl. Phys. 113, 183516 (2013).

32. Kasa, R. \& Adachi, S. Mn-activated $\mathrm{K}_{2} \mathrm{ZrF}_{6}$ and $\mathrm{Na}_{2} \mathrm{ZrF}_{6}$ phosphors: sharp red and oscillatory blue-green emissions. J. Appl. Phys. 112, 013506 (2012).

33. Adachi, S. \& Takahashi, T. Direct synthesis and properties of $\mathrm{K}_{2} \mathrm{SiF}_{6}: \mathrm{Mn}^{4+}$ phosphor by wet chemical etching of Si wafer. J. Appl. Phys. 104, 023512 (2008).

34. Xu, Y. K. \& Adachi, S. Properties of $\mathrm{Mn}^{4+}$-activated hexafluorotitanate phosphors. J. Electrochem. Soc. 158, J58-J65 (2011).

35. Setlur, A. A. et al. Energy-efficient, high-color-rendering LED lamps using oxyfluoride and fluoride phosphors. Chem. Mater. 22, 4076-4082 (2010).

36. Gobël, O. Rerefinement of $\mathrm{K}_{2}\left[\mathrm{TiF}_{6}\right]$. Acta Crystallogr. C 56, 521-522 (2000).

37. Shannon, R. D. Revised effective ionic-radii and systematic studies of interatomic distances in halides and chalcogenides. Acta Crystallogr. A 32, 751-767 (1976).

38. Chodos, S. L., Black, A. M. \& Flint, C. D. Vibronic spectra and lattice-dynamics of $\mathrm{Cs}_{2} \mathrm{MnF}_{6}$ and $\mathrm{A}_{2} \mathrm{MF}_{6}: \mathrm{MnF}_{6}^{2-}$. J. Chem. Phys. 65, 4816-4824 (1976).

39. Helmholz, L. \& Russo, M. E. Spectra of manganese(IV) hexafluoride ion $\left(\mathrm{MnF}_{6}^{2-}\right)$ in environments of $\mathrm{O}_{\mathrm{h}}$ and $\mathrm{D}_{3 \mathrm{~d}}$ symmetry. J. Chem. Phys. 59, 5455-5470 (1973).
40. Krämer, K. W. et al. Hexagonal sodium yttrium fluoride based green and blue emitting upconversion phosphors. Chem. Mater. 16, 1244-1251 (2004).

41. Dong, C. H. \& van Veggel, F. C. J. M. Cation exchange in lanthanide fluoride nanoparticles. ACS Nano. 3, 123-130 (2009).

42. Dong, C., Korinek, A., Blasiak, B., Tomanek, B. \& van Veggel, F. C. J. M. Cation exchange: a facile method to make $\mathrm{NaYF}_{4}: \mathrm{Yb}, \mathrm{Tm}-\mathrm{NaGdF}_{4}$ core-shell nanoparticles with a thin, tunable, and uniform shell. Chem. Mater. 24, 1297-1305 (2012).

43. Son, D. H., Hughes, S. M., Yin, Y. \& Paul Alivisatos, A. Cation exchange reactions in ionic nanocrystals. Science 306, 1009-1012 (2004).

44. Robinson, R. D. et al. Spontaneous superlattice formation in nanorods through partial cation exchange. Science 317, 355-358 (2007).

45. Tanabe, Y. \& Sugano, S. On the absorption spectra of complex ions II. J. Phys. Soc. Jpn 9, 766-779 (1954).

46. Henderson, B. \& Imbusch, G. F. Optical Spectroscopy of Inorganic Solids (Oxford University Press, 1989).

47. Reisfeld, M. J., Matwiyoff, N. A. \& Asprey, L. B. The electronic spectrum of cesium hexafluoromanganese(IV). J. Mol. Spectrosc. 39, 8-20 (1971).

48. Forrest, I. W. \& Lane, A. P. Single-crystal polarized infrared and Raman-spectra and normal-coordinate analysis of some group 4 complex hexafluorometalates. Inorg. Chem. 15, 265-269 (1976).

49. Pfeil, A. Vibrational analysis of Raman, infrared and electronic spectra of hexafluoromanganate(IV). Theor. Chim. Acta 20, 159-170 (1971).

50. Bachmann, V., Ronda, C. \& Meijerink, A. Temperature quenching of yellow $\mathrm{Ce}^{3+}$ luminescence in YAG:Ce. Chem. Mater. 21, 2077-2084 (2009).

51. Bhushan, S. \& Chukichev, M. V. Temperature-dependent studies of cathodoluminescence of green band of $\mathrm{ZnO}$ crystals. J. Mater. Sci. Lett. 7, 319-321 (1988).

52. Wang, S. S. et al. Neighboring-cation substitution tuning of photoluminescence by remote-controlled activator in phosphor lattice. J. Am. Chem. Soc. 135, 12504-12507 (2013).

53. Birkel, A. et al. Rapid microwave preparation of highly efficient $\mathrm{Ce}^{3+}$. substituted garnet phosphors for solid state white lighting. Chem. Mater. 24, 1198-1204 (2012).

54. Lin, C. C. et al. Improving optical properties of white LED fabricated by a blue LED chip with yellow/red phosphors. J. Electrochem. Soc. 157, H900-H903 (2010).

55. Li, Y. -L., Huang, R. \& Lai, Y. H. Efficiency droop behaviors of InGaN/GaN multiple-quantum-well light-emitting diodes with varying quantum well thickness. Appl. Phys. Lett. 91, 181113 (2007).

56. Bode, H., Jenssen, H. \& Bandte, F. Uber eine neue darstellung des kalium-hexafluoromanganats(IV). Angew. Chem-Ger. Ed. 65, 304-304 (1953).

57. Ohno, Y. Color rendering and luminous efficacy of white LED spectra. Proc. SPIE 5530, 88-98 (2004)

\section{Acknowledgements}

This work was supported by the CAS/SAFEA International Partnership Program for Creative Research Teams, the Special Project of National Major Scientific Equipment Development of China (No. 2012YQ120060), the 973 program of MOST (no. 2014CB845605), the NSFC (nos 11004191, U1305244 and 21325104), the Key Project of Science and Technology Foundation of Fujian Province (nos 2011HZ0001-2 and 2013I0009), the Fujian Provincial Natural Science Foundation for Young Scientists (No. 2014J05070) and the Ministry of Science and Technology of Taiwan (Contract no. MOST 101-2113-M-002-014-MY3).

\section{Author contributions}

H.Z. and X.C. conceived the experiments and wrote the paper. H.Z. is primarily responsible for the experiments. S.S., C.C.L., Z.L., R.S.L. and Y.C. fabricated and characterized the white LEDs. Y.L. and J.K. synthesized the $\mathrm{NaGdF}_{4}$ and $\mathrm{NaYF}_{4}$ crystals, respectively. W.L. and E.M. carried out RT PL decays measurements. All the authors discussed the results and manuscript.

\section{Additional information}

Supplementary Information accompanies this paper at http://www.nature.com/ naturecommunications

Competing financial interests: The authors declare no competing financial interests.

Reprints and permission information is available online at http://npg.nature.com/ reprintsandpermissions/

How to cite this article: Zhu, H. et al. Highly efficient non-rare-earth red emitting phosphor for warm white light-emitting diodes. Nat. Commun. 5:4312 doi: 10.1038/ncomms5312 (2014). 